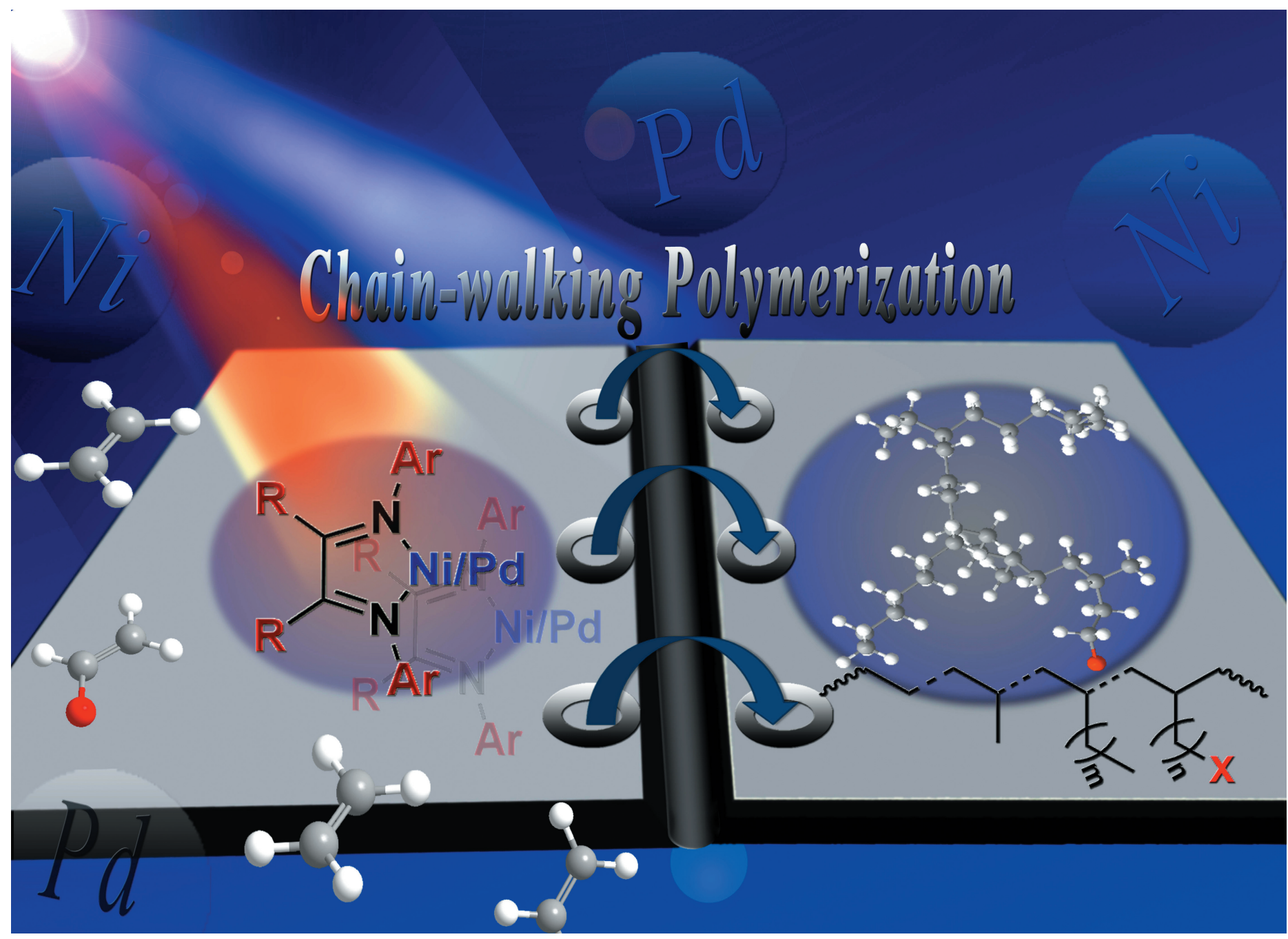

Highlighting results from the University of Science and Technology of China, Hefei, China.

A continuing legend: the Brookhart-type $\alpha$-diimine nickel and palladium catalysts

Fuzhou Wang and Changle Chen summarize some of the recent advances in $\alpha$-diimine ligand developments, as well as some new and challenging monomers that this class of catalysts can address through these ligand improvements.

\section{As featured in:}

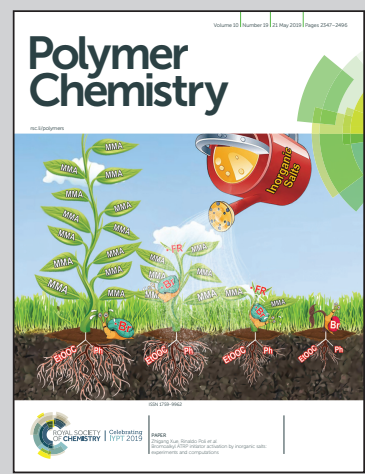

See Fuzhou Wang and Changle Chen, Polym. Chem., 2019, 10, 2354. 


\section{D) Check for updates}

Cite this: Polym. Chem., 2019, 10 2354

Received 13th February 2019 , Accepted 17th April 2019

DOI: 10.1039/c9py00226j

rsc.li/polymers

\title{
A continuing legend: the Brookhart-type $\alpha$-diimine nickel and palladium catalysts
}

\begin{abstract}
Fuzhou Wang (iD) a and Changle Chen (D) *b
The Brookhart-type $\alpha$-diimine nickel and palladium catalysts are one of the most examined systems in the field of olefin polymerization. Even after more than twenty years of extensive research, they continue to attract a lot of attention. In addition to their ease of synthesis and structural versatility, the chain walking capability and great polar group tolerance represent some of their most fascinating features. Followed by some brief descriptions of the chain walking mechanism, this review summarizes some recent advances in $\alpha$-diimine ligand modifications. Specifically, it is categorized into three aspects: modifications of $N$-aryl substituents, modifications of ligand backbone structures, and the utilization of dinucleating ligands. Influences of steric and electronic effects on catalytic properties are demonstrated. Some recent developments in copolymerizations of olefins with polar comonomers to produce functionalized polyolefin materials are also discussed.
\end{abstract}

${ }^{a}$ Institute of Physical Science and Information Technology, Anhui University, Hefei 230601Anhui, China

${ }^{b}$ CAS Key Laboratory of Soft Matter Chemistry, Department of Polymer Science and Engineering, University of Science and Technology of China, Hefei 230026, China. E-mail: changle@ustc.edu.cn

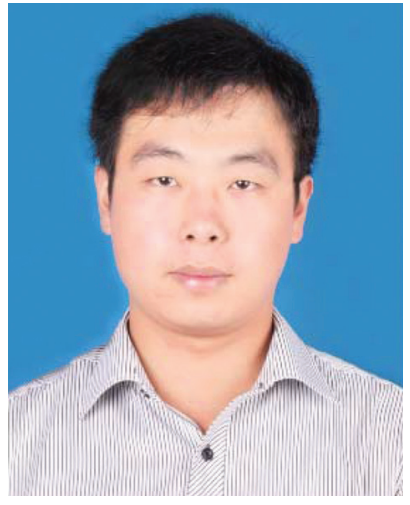

Fuzhou Wang
Fuzhou Wang received his MS degree in 2013 from Northwest Normal University. He carried out his doctoral work in polymer chemistry at Hiroshima University under the direction of Prof. Takeshi Shiono from 2013 to 2017. Subsequently, he joined Prof. Changle Chen's group at the University of Science and Technology of China as a research assistant. In 2018, he joined Anhui University as a special associate researcher. His current research interest is focused on olefin polymerization by late transition metal catalysts.

\section{Introduction}

Polyolefins have been playing pivotal roles in the polymer industry as well as in our daily lives. ${ }^{1}$ After two decades of research, late-transition metal catalysts based on $\mathrm{Ni}$ and $\mathrm{Pd}$ for olefin polymerization have received extensive attention owing to their low oxophilicity, and correspondingly the potential in copolymerizing olefins with polar comonomers. ${ }^{2,3}$ Specifically,

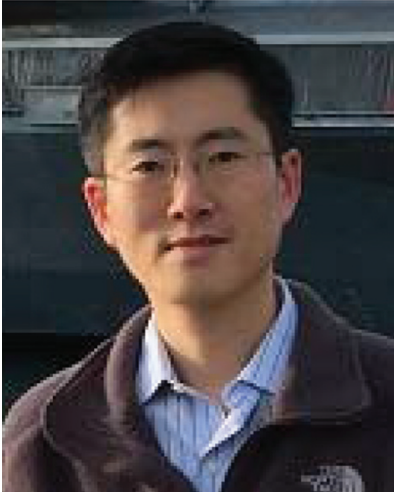

Changle Chen
Changle Chen obtained his B.S. degree from the University of Science and Technology of China (2005), and PhD from the University of Chicago (2010). After postdoctoral studies at Northwestern University and some time at Celanese Corporation, he started his independent career as a professor at USTC in 2013. His current research focuses on the development of new catalysts and new strategies for olefin polymerization and copolymerization. His notable awards include American Chemical Society DIC Young Investigator Award, IUPAC PrizesHonorable Mention, Chinese Chemical Society Award for Outstanding Young Chemist, Society of Polymer Science Japan International Leading Young Scientist and NSFC Excellent Young Scholar Fellowship. 
the seminal studies by Brookhart and co-workers on the discovery of cationic $\alpha$-diimine-based $\mathrm{Ni}$ and Pd catalysts (Fig. 1) really marked the start of this new era in olefin polymerization studies. $^{4,5}$ Branched polyolefins are generally produced by early transition metal catalyzed ethylene copolymerization with $\alpha$-olefins. In contrast, this type of catalyst (C1a and C1b) can produce branched polyolefins using only ethylene as the feedstock. This is achieved through their characteristic chain walking process, which has been extensively studied both experimentally and theoretically. ${ }^{5,6}$ More importantly, the palladium catalysts are able to copolymerize olefins with polar comonomers to afford copolymers containing functional groups without the pre-protection of the polar groups. ${ }^{7,8}$

Recently, phosphine-containing palladium catalysts have emerged as powerful alternatives for ethylene copolymerization with polar comonomers. ${ }^{9-21}$ Some of these catalysts possessed comparably even better properties than $\alpha$-diimine palladium catalysts in copolymerization reactions. However, the Brookhart-type $\alpha$-diimine-based precatalysts continue to be of great research interest for the reasons that include: (i) the ease of synthesis for both the ligands and the metal complexes, (ii) the versatility of the ligand structures, (iii) the ability to tune the polymer microstructures such as branching and topologies, etc. ${ }^{22}$ As a matter of fact, it is truly amazing that great efforts are still being made nowadays concerning Brookhart catalysts from all around the world, even after twenty years of intensive research.

Over the past few years, there have been numerous review articles concerning $\alpha$-diimine $\mathrm{Ni}$ and Pd catalysts, with aspects including the chain walking mechanism, ligand structures, different monomers, and polymer properties. ${ }^{23-32}$ However, there have been some major advances recently concerning catalyst developments, ${ }^{33}$ which allowed far greater control over the polymerization process as well as polymer microstructures. Most importantly, the suitable polar monomer substrate scope has been significantly expanded through these catalyst developments. Here we will summarize some of the advances in $\alpha$-diimine ligand developments since 2013, as well as some new and challenging monomers that this class of catalysts can address through these ligand improvements. First, the chain walking mechanism is briefly discussed for readers who are not familiar with this field. The $\alpha$-diimine ligand family has continued to grow rapidly. It seems that this is only limited by the chemists' imagination and their synthesis capabilities. We do not intend to provide a comprehensive review of all the $\alpha$-diimine ligands in this field. Instead, only selected examples
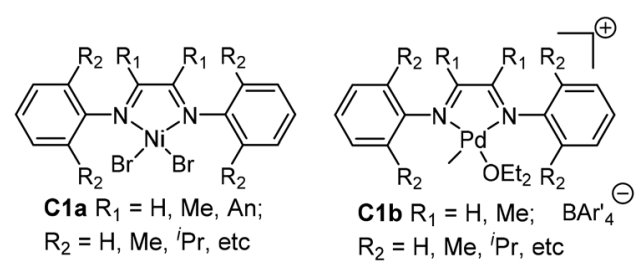

Fig. 1 Brookhart's $\mathrm{Ni}$ and $\mathrm{Pd} \alpha$-diimine-based precatalysts. ${ }^{4,5}$ in recent years will be discussed. Special attention is paid to the cases with unique catalytic properties. Finally, $\alpha$-diimine $\mathrm{Ni}$ and Pd mediated copolymerization of olefins with polar comonomers will be described. The polar monomer substrate scope with Brookhart type catalysts has been greatly expanded in recent years; much of the success has been enabled through ligand modifications.

\section{Chain walking mechanism}

\subsection{Chain walking ethylene polymerization}

In ethylene polymerization, these Brookhart catalysts demonstrated good thermal stability and high activities to yield high molecular weight polyolefins with unique branched structures because of the chain walking process. Fink and co-workers ${ }^{34}$ originally presented a possible chain walking mechanism which was subsequently developed by Brookhart and coworkers. ${ }^{4,5}$ Scheme 1 shows the mechanism of insertion and chain walking for ethylene polymerization. The chain propagation, chain transfer, and chain walking or isomerization are the major steps. During controlled chain walking polymerization, the cationic metal center migrated along the polymer backbone through a rapid $\beta-\mathrm{H}$ elimination reaction and reinsertion with opposite regio-chemistry. This can occur many times before ethylene trapping. Subsequently, methyl and longer chain branches were generated from ethylene trapping and insertion of the secondary metal-alky species. As such, alkyl chains included Me, Et, $n$-Pr, $n$-Bu, and sec-Bu branches and longer chains can be generated in ethylene polymerization. ${ }^{3,35}$

Recently, Gao and co-workers have proposed a different mechanistic model for the $\alpha$-diimine $\mathrm{Ni}$ catalyzed ethylene chain walking process. ${ }^{36}$ One-step chain walking followed by ethylene insertion gives a methyl branch. Meanwhile, longchain branching (LCB) is obtained by ethylene insertion into the primary Ni-alkyl species originating from nickel migration to the methyl terminal, because of restricted ethylene insertion into the secondary Ni-alkyl species with an $\alpha$-ethyl or a bulkier alkyl.

Different ligand backbone structures and their $N$-aryl substituents (Scheme 2) can provide various coordination environ-

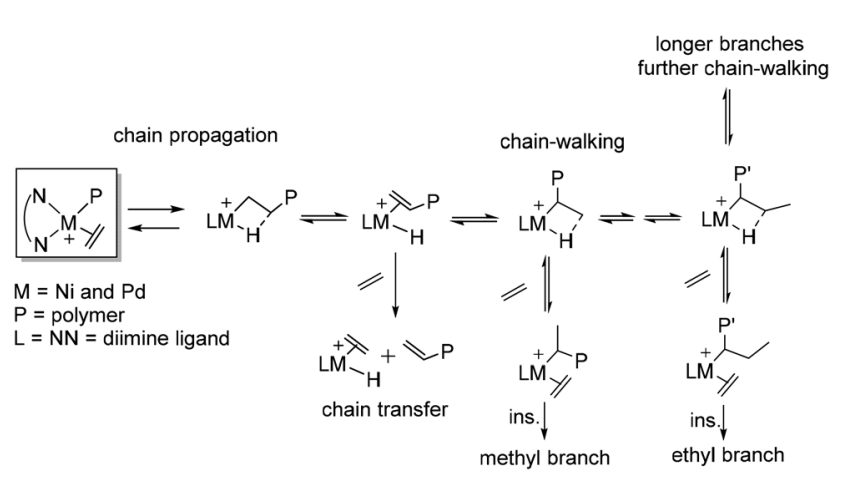

Scheme 1 Mechanism of chain walking ethylene polymerization. 


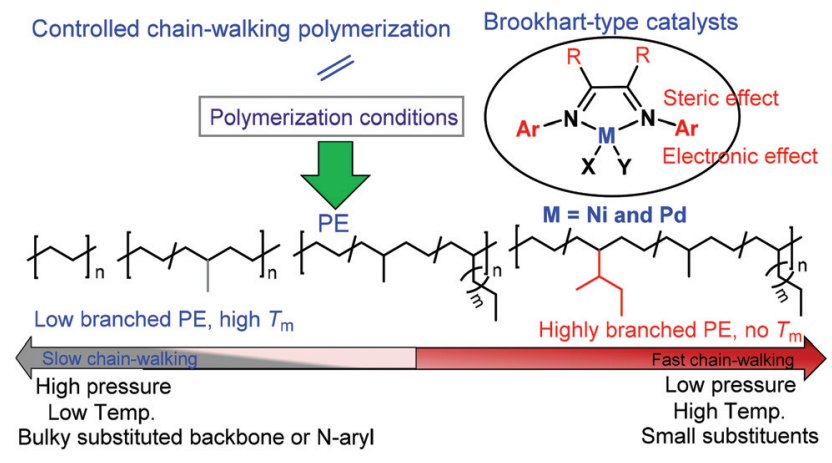

Scheme 2 Influence of the chain walking process by ligand structures and polymerization conditions.

ments and electronic and steric influences over the metal center, which correspondingly modulate the chain walking behavior and control the polymer microstructures. ${ }^{8,37}$ For example, it has been demonstrated that the substituents on the backbone of $\alpha$-diimine ligands can significantly influence the molecular weights and branching densities of the polyethylene products. ${ }^{38,39}$ The ligand electronic effect is also highly important. ${ }^{40-43}$ For example, Guan and co-workers showed that the electron withdrawing substituent can increase the electrophilicity of the metal center, which favors chain propagation to yield higher molecular weight polyethylenes (PEs). ${ }^{43}$ Furthermore, polymer topology can be controlled via polymerization conditions (Scheme 2). ${ }^{8,29}$ For example, Guan and co-workers demonstrated that polyethylene topology can be changed from a hyperbranched structure at low ethylene pressures to a relatively linear structure at high pressures. ${ }^{37,44}$ Interestingly, Long and co-workers have recently demonstrated that the polyethylene microstructure can be tuned by visible light irradiation. ${ }^{45}$

\subsection{Chain walking $\alpha$-olefin polymerization}

The mechanism for chain walking $\alpha$-olefin polymerization is outlined in Scheme $3{ }^{46,47}$ Consecutive 1,2-insertion of $\alpha$-olefins gives an $n$-alkyl $\left(\mathrm{C}_{\omega-2}\right)$ branch, while 1,2-insertion followed by chain walking and insertion gives a methyl branch $(\omega, 2$-enchainment $) .^{48}$ In contrast, 2,1-insertion and complete chain walking lead to chain-straightening with the formation of a long methylene sequence ( $\omega, 1$-enchainment). ${ }^{44}$ Coates and co-workers have recently revised and updated the mechanistic picture of $\alpha$-olefin insertion pathways to analyze and explain the overall branching microstructure (Scheme 3). ${ }^{46}$ The ${ }^{13} \mathrm{C}$ NMR analyses of poly( $\alpha$-olefins) produced from monomers with ${ }^{13} \mathrm{C}$-labeled carbons showed 2,1- or 1,2-insertion from the primary chain end position $\left(1^{\circ}\right)$, the penultimate chain end position $\left(2 \mathrm{p}^{\circ}\right)$, secondary positions on the polymer backbone $\left(2^{\circ}\right)$, and previously installed methyl groups $\left(1 \mathrm{~m}^{\circ}\right)$. Therefore, various branched polyolefins containing methyl, different alkyl branches and long methylene sequences can be obtained. ${ }^{46,47}$ In a similar situation to ethylene polymerization, the chain

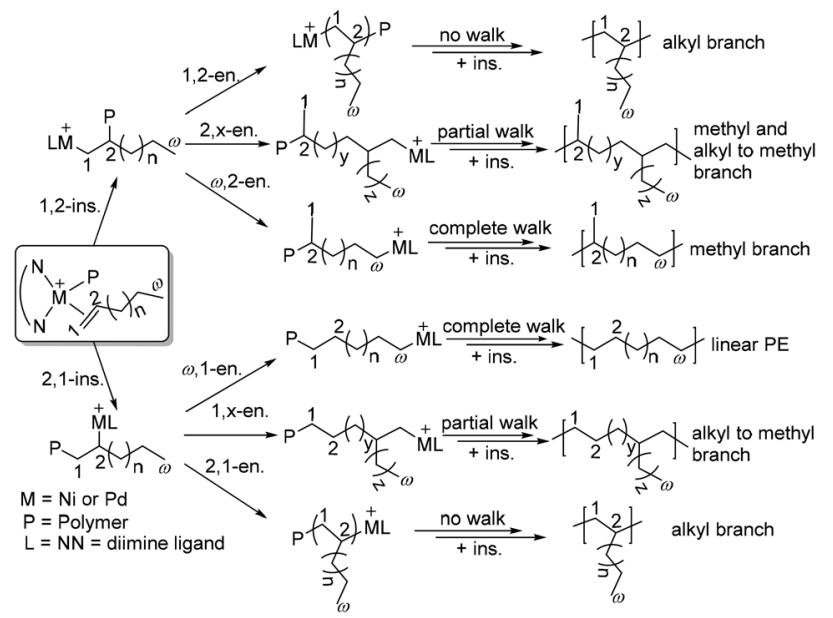

Scheme 3 Mechanism of chain walking $\alpha$-olefin polymerization. ${ }^{46}$

walking process is influenced by ligand structures and polymerization conditions.

Living $\alpha$-olefin polymerization is an important technique to obtain predictable polymer molecular weights as well as block copolymers. ${ }^{49}$ In addition, the control of the chain walking process to achieved regio- and stereo-selectivity in $\alpha$-olefin polymerization represents a great challenge. ${ }^{49-53}$ Coates and co-workers reported living polymerization of propylene and higher $\alpha$-olefins catalyzed by a $C_{2}$-symmetric chiral sec-phenethyl substituted $\alpha$-diimine nickel complex. ${ }^{50,51}$ The regioselectivity of these catalysts varied significantly with reaction temperatures: regioregular polypropylene (PP) with a high isotactic content was generated at $-60{ }^{\circ} \mathrm{C}$, but regioirregular PP was formed at elevated temperature. ${ }^{50}$ Therefore, regio-block PP can be generated by changing the polymerization temperature. Guan and co-workers showed that some cyclophane $\alpha$-diimine nickel catalysts can realize living propylene polymerization at $50-75{ }^{\circ} \mathrm{C} .{ }^{53-56}$ Recently, Coates and co-workers have demonstrated that $\alpha$-diimine-nickel complexes catalyzed 1-butene polymerization in a stereo-retentive fashion to yield semicrystalline polyolefin, i.e., poly(1-propylpentan-1,5-diyl) ${ }^{53}$

\section{Modified Brookhart-type $\alpha$-diimine catalysts}

Ligand structures are crucial in determining the properties of Brookhart catalysts. Significant advances have been made in the design and modifications of the ligand backbones and the $\mathrm{N}$-aryl substituents. ${ }^{24,28}$ It is well established that bulky $N, N$ diaryl-substituents were required to enable high stability, high activity, high polymer molecular weights and high melting temperatures $\left(T_{\mathrm{m}}\right)$. In this section, we categorize the studies on ligand modifications into three classes: (1) modifications of the $N$-aryl substituents (Fig. 2-14), (2) modifications of the ligand backbone (Fig. 15-17), and (3) utilization of dinucleating ligands (Fig. 18-21). 

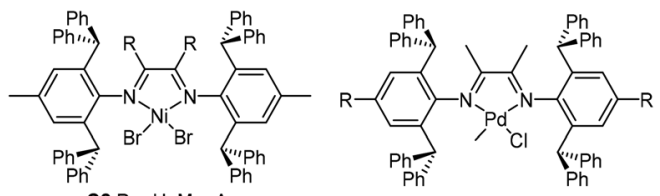

$\mathrm{C} 2 \mathrm{R}=\mathrm{H}, \mathrm{Me}, \mathrm{An}$

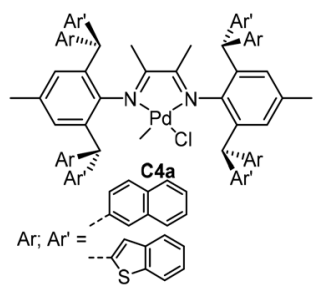

$\mathrm{C} \mathrm{R}^{=} \mathrm{OMe}, \mathrm{Me}, \mathrm{Cl}, \mathrm{CF}_{3}$

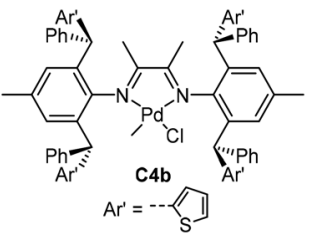

Fig. 2 2,6-Diarylhydryl-based $\alpha$-diimine $\mathrm{Ni}$ and Pd catalysts. ${ }^{57-62}$

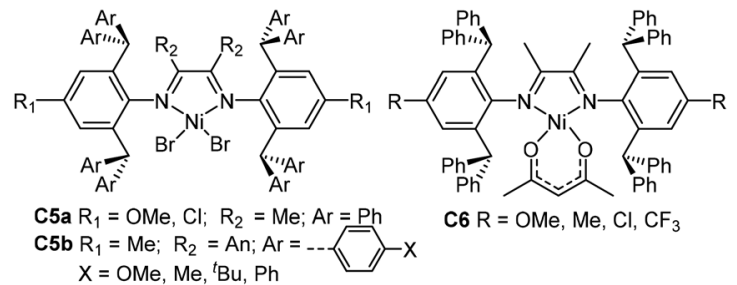

Fig. 3 2,6-Dibenzhydryl-based $\alpha$-diimine Ni catalysts. ${ }^{63,64}$
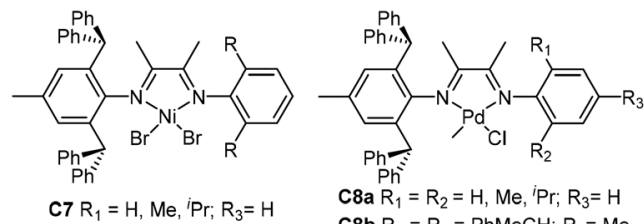

C8b $\mathrm{R}_{1}=\mathrm{R}_{2}=\mathrm{PhMeCH} ; \mathrm{R}_{3}=\mathrm{Me}$

C8c $\mathrm{R}_{1}=\mathrm{PhMeCH} ; \mathrm{R}_{2}=\mathrm{Ph}_{2} \mathrm{CH} ; \mathrm{R}_{3}=\mathrm{Me}$

Fig. 4 2,6-Dibenzhydryl-based unsymmetrical $\alpha$-diimine $\mathrm{Ni}$ and $\mathrm{Pd}$ complexes. ${ }^{65-67}$

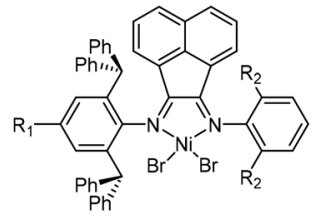

C9a $\mathrm{R}_{1}=\mathrm{F}, \mathrm{Cl}, \mathrm{NO}_{2},{ }^{\mathrm{t}} \mathrm{Bu}, \mathrm{CHPh}_{2}$; $\mathrm{R}_{2}=\mathrm{Me},{ }^{\mathrm{i}} \mathrm{Pr}$

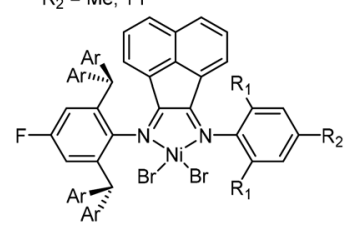

$\mathrm{C} 10 \mathrm{Ar}=p-\mathrm{F}-\mathrm{C}_{6} \mathrm{H}_{5}-; \mathrm{R}_{1}=\mathrm{Me},{ }^{\mathrm{i}} \mathrm{Pr}$ $\mathrm{R}_{2}=\mathrm{H}, \mathrm{Me}$

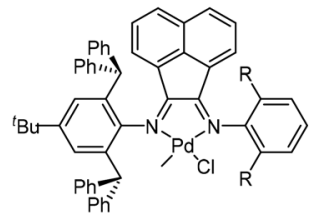

C9b R $=$ Me, Et, ${ }^{i} \mathrm{Pr}$

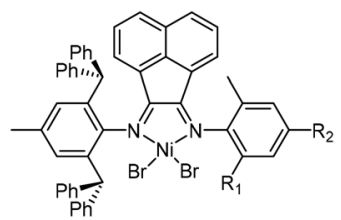

C11 $\mathrm{R}_{1}=$ Cyclooctyl, Cyclohexyl, Cyclopentyl; $\mathrm{R}_{2}=\mathrm{H}, \mathrm{Me}$
Fig. 5 2,6-Dibenzhydryl-based unsymmetrical acenaphthene $\mathrm{Ni}$ - and Pd-diamine complexes. ${ }^{68-75}$

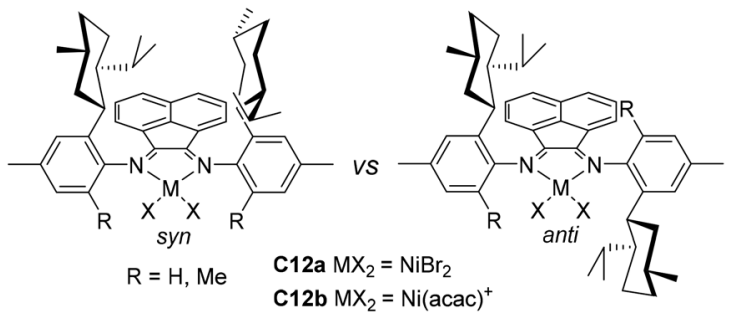

Fig. 6 ortho-Menthyl substituted $\alpha$-diimine-based $\mathrm{Ni}$ and $\mathrm{Pd}$ complexes. ${ }^{76}$

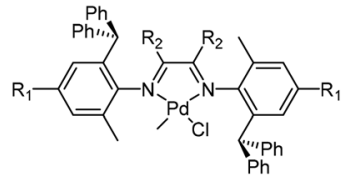

C13a $\mathrm{R}_{1}=\mathrm{OMe}, \mathrm{Me}, \mathrm{Cl}, \mathrm{CF}_{3} ; \mathrm{R}_{2}=\mathrm{Me}$ C13b $R_{1}=M e ; R_{2}=A n$

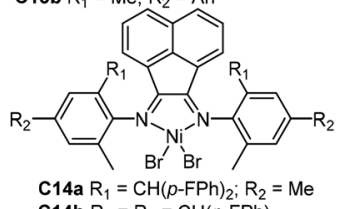
C14b $R_{1}=R_{2}=\mathrm{CH}(p-\mathrm{FPh})_{2}$

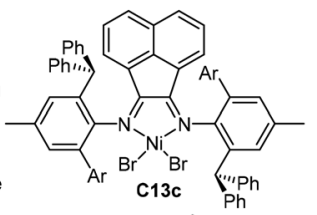

$\mathrm{Ar}=$

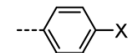

$\left.\mathrm{X}=\mathrm{H}, \mathrm{Me},{ }^{\mathrm{t}} \mathrm{Bu}\right)$
Fig. 7 Unsymmetrical ortho-dibenzhydryl-substituted $\alpha$-diimine-based $\mathrm{Ni}$ and $\mathrm{Pd}$ complexes. ${ }^{77-80}$

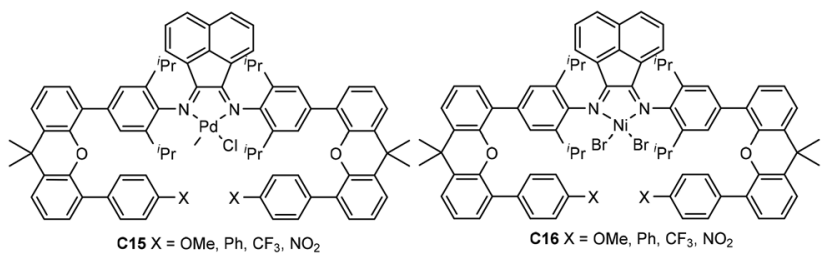

Fig. 8 Xanthene-bridged $\alpha$-diimine-based Pd and Ni complexes. ${ }^{81,82}$

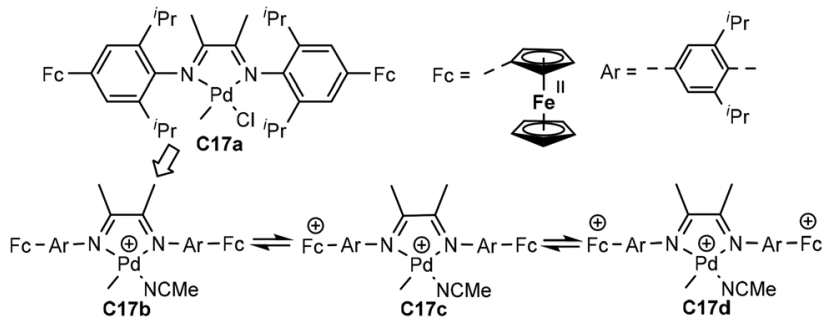

Fig. 9 para-Ferrocene-based $\alpha$-diimine Pd catalysts. ${ }^{83}$

\subsection{Modifications of the $\mathrm{N}$-aryl substituents}

In 2013, Long and co-workers reported studies of some cationic ortho-dibenzhydryl substituted $\alpha$-diimine nickel complexes C2 (Fig. 2). ${ }^{57-59}$ These complexes displayed remarkable thermal stability, maintaining high activity of up to $2.85 \times 10^{6}$ $\mathrm{g}$ PE (mol Ni h) $)^{-1}\left(100{ }^{\circ} \mathrm{C}, 10 \mathrm{~min}\right) .{ }^{57}$ In addition, moderately branched polyethylenes (63-75 branches/1000 C) with high $M_{\mathrm{n}}$ 

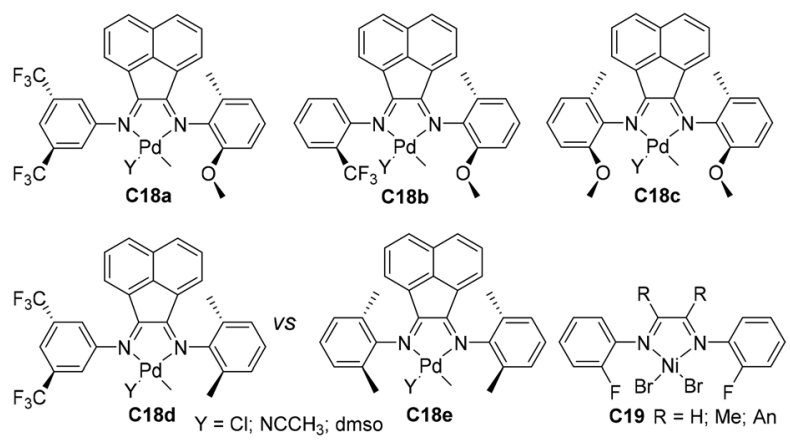

Fig. 10 Structures of the $\mathrm{CF}_{3}$, methoxy substituted and fluorinated $\alpha$-diimine-based $\mathrm{Pd}$ and $\mathrm{Ni}$ complexes. ${ }^{88-90}$

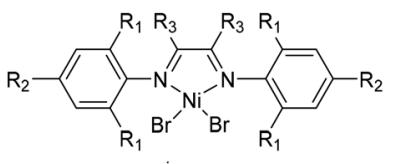

C20a R $\mathrm{R}_{1}=\mathrm{Me},{ }^{i} \mathrm{Pr} ; \mathrm{R}_{2}=\mathrm{CH}_{2}\left(\mathrm{CF}_{2}\right)_{4} \mathrm{CF}_{2}$; $\mathrm{R}_{3}=\mathrm{H}, \mathrm{Me}, \mathrm{An}$ C2Ob $\mathrm{R}_{1}=\mathrm{Me} ; \mathrm{R}_{2}=\mathrm{CH}_{2}\left(\mathrm{CF}_{2}\right)_{5} \mathrm{CF}_{2} ; \mathrm{R}_{3}=\mathrm{H}$

Fig. 11 para-Fluorinated alkyl substituted $\alpha$-diimine $\mathrm{Ni}$ - and $\mathrm{Pd}$-based complexes. $^{91}$
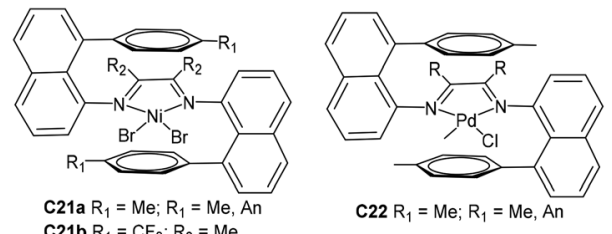

Fig. 12 "Sandwich"-type naphthyl $\alpha$-diimine $\mathrm{Ni}-$ and $\mathrm{Pd}$-based catalysts. $^{91-95}$
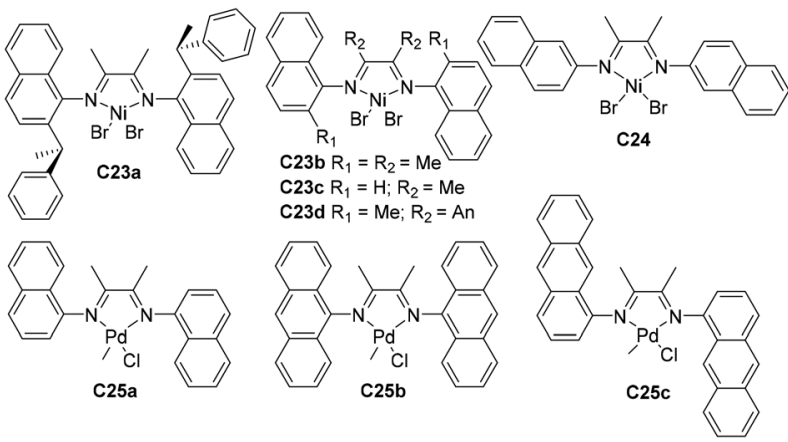

Fig. 13 Structure of $N$-aryl $\alpha$-diimine $\mathrm{Ni}$ - and Pd-based catalysts. ${ }^{96-98}$

values $\left(>6 \times 10^{5} \mathrm{~g} \mathrm{~mol}^{-1}\right)$ and narrow polydispersities $\left(M_{\mathrm{w}} / M_{\mathrm{n}}\right.$ $\leq 1.31$ ) were generated. This type of catalyst showed the characteristics of living polymerization even at $75^{\circ} \mathrm{C}$. It is well known that sterically bulky substituents in $\alpha$-diimine systems can improve catalyst stability and polymer molecular weights. However, the great performances of catalysts $\mathbf{C} 2$ exceeded

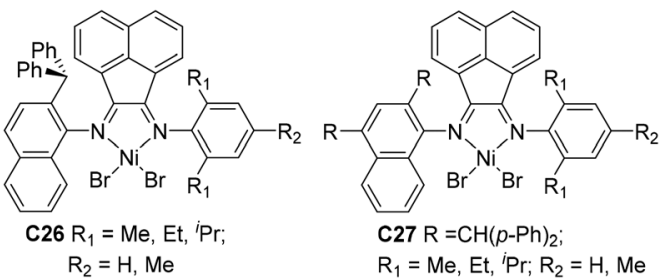

Fig. 14 Unsymmetrical naphthyl-imine Ni catalysts. ${ }^{99,100}$

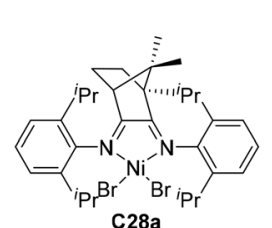

C28a

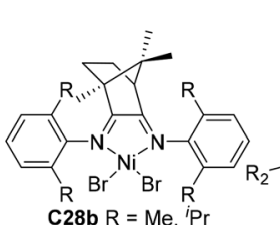

C28b $\mathrm{R}=\mathrm{Me}{ }^{i} \mathrm{Pr}$

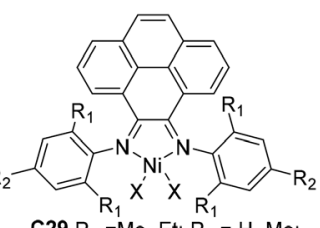

C29 $R_{1}=M e, E t ; R_{2}=H, M e$;
Fig. 15 Skeletal modifications in $\alpha$-diimine Ni-based catalysts. ${ }^{101,102}$

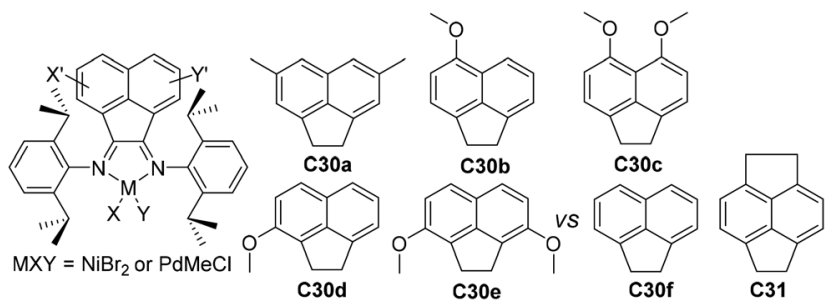

Fig. 16 Modified acenaphthyl (An) backbone in $\alpha$-diimine $\mathrm{Ni}$ - and Pdbased catalysts. ${ }^{103,104}$

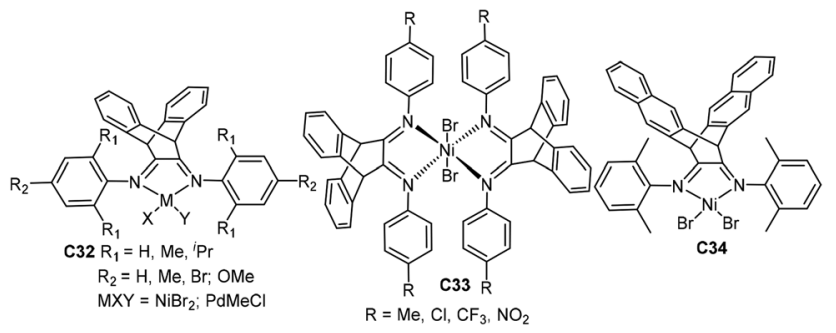

Fig. 17 Three-dimensional geometry $\mathrm{Ni}$ - and Pd-based $\alpha$-diimine complexes with a bulky bridged backbone. ${ }^{105-111}$

general expectations, and inspired numerous research groups to further study related ligands and catalysts.

Because of the sterically bulky nature, it is quite challenging to prepare these $\alpha$-diimine ligands. In the initial reports, quite low yields ( $\mathrm{ca} .10 \%$ ) were reported for the ligand synthesis. $^{57-59}$ In 2015, Chen and co-workers developed a modified procedure, which can synthesize this type of ligand at yields of above $90 \% .{ }^{60}$ Utilizing the modified procedure, some ligands containing either electron-donating or electrowithdrawing groups ( $\mathrm{OMe}, \mathrm{Me}, \mathrm{Cl}$ and $\mathrm{CF}_{3}$ ) were prepared. The corresponding $\alpha$-diimine palladium catalysts C3 (Fig. 2) dis- 


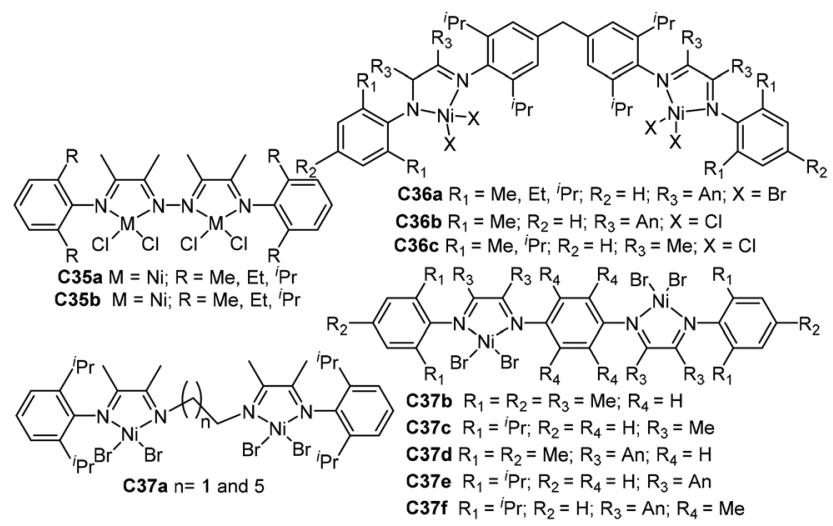

Fig. $18 \mathrm{~N}, \mathrm{~N}$-Alkyl-bridged and aryl-linked dinculear $\alpha$-diimine $\mathrm{Ni}$ and Pd precatalysts. ${ }^{113-117}$

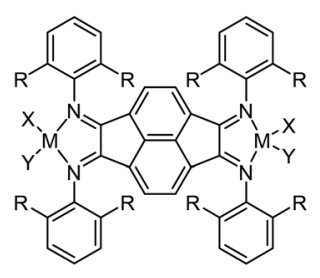

C38a $\mathrm{R}=\mathrm{Me},{ }^{i} \mathrm{Pr} ; \mathrm{MXY}=\mathrm{NiBr}_{2}$ C38b $\mathrm{R}=\mathrm{Me},{ }^{i} \mathrm{Pr} ; \mathrm{MXY}=\mathrm{PaMeC}$

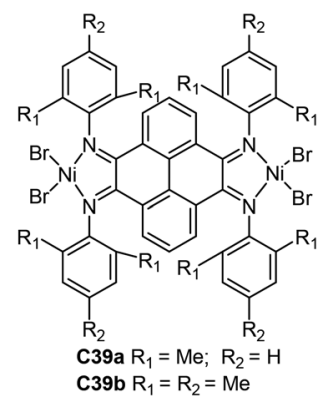

Fig. 19 Conjugated-backbone $\alpha$-diimine binuclear $\mathrm{Ni}$ and $\mathrm{Pd}$ catalysts. $^{118,119}$
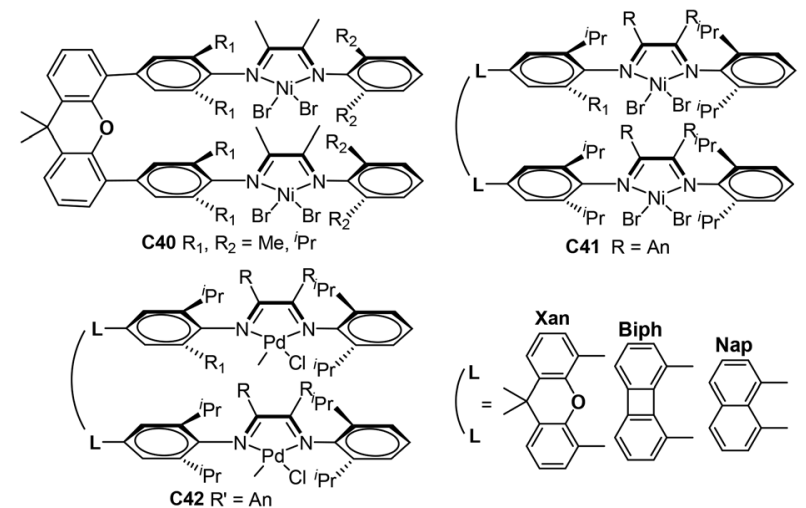

Fig. 20 Xanthene-, naphthalene- and biphenylene-bridged dinuclear $\mathrm{Ni}$ and $\mathrm{Pd} \alpha$-diimine precatalysts. ${ }^{120,121}$

played high thermal stability, high activities of up to $3.2 \times 10^{6}$ $\mathrm{g}$ PE (mol Pd h$)^{-1}\left(60^{\circ} \mathrm{C}, 15 \mathrm{~min}\right)$, and high polymer $M_{\mathrm{n}}$ (up to $538000)$ in ethylene polymerization. More interestingly, semicrystalline low-density branched (23-29/1000 C) PEs with high $T_{\mathrm{m}}$ of up to $99{ }^{\circ} \mathrm{C}$ were obtained. Semicrystalline ethylene/ methyl acrylate copolymers can also be generated through copolymerizations. This represents a very unique property for these and subsequently developed diarylhydryl based

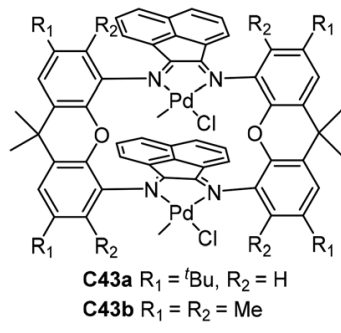

Fig. 21 Double-decker structure of dinuclear $\alpha$-diimine $\mathrm{Pd}$ catalysts. ${ }^{122-124}$

$\alpha$-diimine palladium precatalysts. The majority of the previously reported $\alpha$-diimine based palladium precatalysts led to the formation of highly branched (usually >80/1000 C) polyethylenes or copolymers. As such, totally amorphous polymeric materials with very poor mechanical properties were obtained. The ability to suppress the chain walking process and produce semicrystalline polar functionalized polyolefins is highly fascinating.

Subsequently, the polyethylene branching density can be further lowered to 6/1000 C by two ortho-diarylhydryl-based $\alpha$-diimine palladium catalysts $\mathbf{C 4 a}$ and $\mathbf{C 4 b}$ (Fig. 2) containing naphthalene or (benzo)thiophene groups. ${ }^{61,62}$ Most importantly, very high-molecular-weight polar functionalized copolymers possessing relatively linear microstructures and high $T_{\mathrm{m}}$ values were directly synthesized by copolymerization of ethylene with polar monomers. The ligand electronic effect was investigated in a class of dibenzhydryl-ligated nickel $\alpha$-diimine catalysts C5a and $\mathbf{C 6}$ (Fig. 3). ${ }^{63}$ The $\mathrm{CF}_{3}$-substituted nickel catalyst displayed exceptionally high thermal stability and catalytic activity at elevated polymerization temperatures. The corresponding sterically hindered di(4-X-phenyl)methyl-ligated acenaphthene-nickel catalysts $\mathbf{C 5 b}$ (Fig. 3) possessing different $\mathrm{X}$ substituents (OMe, Me, ${ }^{t} \mathrm{Bu}$ and $\mathrm{Ph}$ ) were also synthesized. ${ }^{64}$ All of these catalysts were highly catalytically active at the level of $10^{6} \mathrm{~g} \mathrm{PE}(\mathrm{mol} \mathrm{Ni} \mathrm{h})^{-1}$ toward ethylene polymerization, and yielded semicrystalline polyethylenes with $M_{\mathrm{n}}$ values larger than one million. In addition, these catalytic systems maintained high catalytic activity and high $M_{\mathrm{n}}$ values at temperatures of up to $100^{\circ} \mathrm{C}$.

Based on these studies, Chen and co-workers have recently explored ethylene and 1-hexene polymerization studies using a class of ortho-dibenzhydryl-based unsymmetric $\mathrm{Ni}$ and $\mathrm{Pd}$ $\alpha$-diimine catalysts (C7 and C8a-c, Fig. 4) containing systematically varied ligand sterics. ${ }^{65,66}$ The branching structures and $M_{\mathrm{n}}$ values of the polymers obtained by these catalysts can be regulated via catalyst structures as well as polymerization conditions. The total branching degrees of the polyethylenes obtained were decreased with increasing $\alpha$-diimine ligand sterics and decreasing reaction temperatures. ${ }^{66}$ The 1-hexene polymerization results indicated that increasing ligand sterics led to enhancement of the chain straightening phenomenon. ${ }^{65}$ The comonomer incorporations and copolymer microstructures can also be tuned in $\mathbf{C 8 a - c}$ catalyzed ethylene copolymer- 
ization of methyl acrylate. These palladium catalysts also generated various branched carboxylic acid-functionalized polyolefins with better control over material properties. ${ }^{67}$

Sun and co-workers synthesized a family of 2,6-dibenzhydryl-based unsymmetrical diiminoacenaphthene nickel catalysts (C9a and C10, Fig. 5) bearing different substituents for ethylene polymerization. ${ }^{68-72}$ Electron-withdrawing groups (F, $\mathrm{Cl}, \mathrm{NO}_{2}$ ) led to great thermal stability and high activities of up to $10^{7} \mathrm{~g}$ PE $(\mathrm{mol} \mathrm{Ni} \mathrm{h})^{-1}$. They also synthesized a class of 2,6dibenzhydryl-based unsymmetrical nickel catalysts C11 (Fig. 5) containing one ring-size variable ortho-cycloalkyl substituted $N$-aryl groups. ${ }^{73}$ Ethylene polymerization using these nickel complexes displayed high activities of up to $1.75 \times 10^{7} \mathrm{~g}$ PE $(\mathrm{mol} \mathrm{Ni} \mathrm{h})^{-1}\left(30^{\circ} \mathrm{C}, 5 \mathrm{~min}\right)$, and generated hyperbranched and moderately branched polyethylene elastomers with $M_{\mathrm{n}}$ values in the range of 2.14-6.68 $\times 10^{5} \mathrm{~g} \mathrm{~mol}^{-1}$ and $T_{\mathrm{m}}$ values as low as $44.2^{\circ} \mathrm{C}$. They recently synthesized some dibenzhydryl-based unsymmetrical $\alpha$-diimine palladium complexes C9b (Fig. 5) bearing different substituents. ${ }^{74,75}$ These palladium complexes activated by methylalminoxanes (MAO) showed high activities for norbornene (NB) homopolymerization, producing insoluble polymers. E-NB copolymerization can also be achieved using these palladium catalysts.

Recently, Jordan and co-workers have synthesized some ortho-menthyl-substituted $\alpha$-diimine-based nickel precatalysts (C12a and C12b, Fig. 6) with both the syn and anti conformers for ethylene polymerization. ${ }^{76}$ ortho-Menthyl-substituted C12b has a preference for the syn conformation, and displayed high activities of $(2.5-6.6) \times 10^{6} \mathrm{~g}$ PE $(\mathrm{mol} \mathrm{Ni} \mathrm{h})^{-1}\left(22^{\circ} \mathrm{C}, 15 \mathrm{~min}\right)$. However, these syn-anti conformers of menthyl-substituted C12b exhibited substantially different polymerization behaviors. The $M_{\mathrm{n}}$ values and branching densities of the polyethylenes generated by the syn conformer were higher than those generated by the anti conformer. The 1-hexene polymerization using the syn conformer showed a greater preference for 6,1enchainment to afford poly(1-hexene) with a high chainstraightening content (syn $50 \%$ vs. anti $41 \%$, Scheme 3 ).

Chen and co-workers have recently synthesized some orthodibenzhydryl substituted unsymmetrical $\alpha$-diimine-based palladium complexes (C13a and C13b, Fig. 7) with different backbone structures and para-substituents (OMe, $\mathrm{Me}, \mathrm{Cl}$ and $\left.\mathrm{CF}_{3}\right) .{ }^{77}$ The ethylene and 1-hexene homopolymerization and ethylene/methyl acrylate (MA) copolymerizations were investigated by these catalysts. The electron-donating para-substituted C13a generated higher molecular weight polymers, and exhibited higher thermal stability. Interestingly, these catalysts produced monodisperse (co)polymers with narrow $M_{\mathrm{w}} / M_{\mathrm{n}}$ values of 1.30-2.05. The corresponding acenaphthene-nickel catalysts containing both dibenzyhydryl and aryl moieties showed great properties to offer polyethylenes with great tensile and elastic properties. ${ }^{78}$ In $\alpha$-olefin polymerizations, this type of catalyst led to a linear monomer unit via the chain walking process. In addition, polar functionalized polyolefins were synthesized by the propylene copolymerizations with 10-undecen-1-ol and methyl 10-undecenoate. Sun and coworkers also developed some unsymmetrical $\alpha$-diimine nickel complexes (C14a ${ }^{79}$ and $\mathbf{C 1 4 b}{ }^{80}$ Fig. 7) bearing ortho-difluorobenzhydryl moieties. These nickel catalysts exhibited high thermal stability and activities $\left(10^{6} \mathrm{~g}\right.$ PE $\left.(\mathrm{mol} \mathrm{Ni} \mathrm{h})^{-1}\right)$, generating high molecular weight PEs with relatively low branching density and narrow $M_{\mathrm{w}} / M_{\mathrm{n}}$ values. It is possible that the sterically bulky dibenzhydryl-substituent prevents syn-anti isomerization in these two systems, or both isomers possess similar properties in ethylene polymerization reactions.

Recently, Chen and co-workers have explored a family of xanthene-containing $\alpha$-diimine nickel and palladium complexes (C15 and C16, Fig. 8) bearing different substituents (OMe, $\mathrm{Ph}, \mathrm{CF}_{3}$ and $\mathrm{NO}_{2}$ ) at a remote position. ${ }^{81,82}$ The steric and electronic factors of the metal center remain largely similar to each other. These palladium complexes C15 demonstrated enhanced thermal stability and polymer molecular weights in comparison with the classic Brookhart-type palladium complex. ${ }^{81}$ The palladium catalyst containing a phenyl group exhibited a much better catalytic activity of up to $2.5 \times$ $10^{4} \mathrm{~g}$ PE $(\mathrm{mol} \mathrm{Pd} \mathrm{h})^{-1}\left(20^{\circ} \mathrm{C}, 12 \mathrm{~h}\right)$ than the rest of the palladium complexes in ethylene polymerization, and produced higher $M_{\mathrm{n}}$ (up to $1.21 \times 10^{5} \mathrm{~g} \mathrm{~mol}^{-1}$ ) PEs with slightly lower branching density. Additionally, E-MA and E-NB copolymerizations were achieved using these palladium catalysts to produce copolymers with high molecular weights. Their thermostable nickel complexes C16 are very active of up to $6.9 \times 10^{6} \mathrm{~g}$ PE $(\mathrm{mol} \mathrm{Ni} \mathrm{h})^{-1}\left(20^{\circ} \mathrm{C}, 30 \mathrm{~min}\right)$, producing moderately branched PEs with very high $M_{\mathrm{n}}$ values of up to $1.53 \times 10^{6} \mathrm{~g} \mathrm{~mol}^{-1}{ }^{82}$ Most importantly, the polyethylene products generated by the Ph-substituted nickel catalyst using only ethylene as feedstock possess excellent elastic properties. This provides an alternative strategy to prepare thermoplastic polyolefin elastomers (TPEs).

Chen and co-workers have recently demonstrated that the pre-installed two ferrocenyl units on the para-aryl position of the palladium complex based $\alpha$-diimine ligand can be oxidized sequentially (C17a-d, Fig. 9). ${ }^{83}$ The catalyst properties were modulated via this stepwise redox process in ethylene and 1-hexene homopolymerization, as well as ethylene copolymerization with methyl acrylate, 5-norbornene-2-yl acetate (NB-Ac) and norbornene. Most interestingly, the microstructures and polydispersities of the produced polymers could be controlled in this stepwise oxidation processes. The concept of redox controlled olefin polymerization has also been realized in $\alpha$-diimine nickel systems as well as some palladium-based catalysts. ${ }^{84-87}$

Milani and co-workers have recently designed a family of sterically open $\alpha$-diimine palladium complexes C18a-e (Fig. 10) bearing trifluoromethyl or methoxy substituents. ${ }^{88}$ These complexes catalyzed the cooligomerization of ethylene with methyl acrylate to generate cooligomers under mild conditions. The ligand structures can significantly affect the catalytic properties. Ahmadjo and co-workers designed some fluorinated nickel $\alpha$-diimine precatalysts C19 (Fig. 10) possessing various backbone structures. ${ }^{89,90}$ The acenaphthoquinone-based catalyst in ethylene polymerization exhibited a moderate activity of $1.4 \times 10^{4} \mathrm{~g}$ PE $(\mathrm{mol} \mathrm{Ni} \mathrm{h})^{-1}\left(30^{\circ} \mathrm{C}\right.$, 
$30 \mathrm{~min}) .{ }^{89}$ Despite the steric openness of these ligands, molecular weights of up to $2.48 \times 10^{5} \mathrm{~g} \mathrm{~mol}^{-1}$ with good crystallinity (58\%) were generated. The introduction of ortho-fluorine into the ligand's $N$-aryl can effectively retard the $\beta$-hydride elimination through the influence of $\mathrm{F}-\mathrm{H}$ bonds, leading to semicrystalline polymers.

Merna and co-workers designed some $\alpha$-diimine-based Pd and Ni complexes C20a-c (Fig. 11) bearing fluorinated alkyl substituents at the para-aryl position. ${ }^{91}$ Propene and 1-hexene were polymerized in a controlled manner by nickel catalysts C20a and C20b at $-10{ }^{\circ} \mathrm{C}$, whereas palladium C20c allowed controlled ethylene polymerization at $0{ }^{\circ} \mathrm{C}$. The effect of parafluoroalkyl groups on the polymerization activities, thermal stability and olefin chain walking process was not significant. The branching densities of the polyolefins obtained by these catalysts can be controlled by the ligand backbones and orthoaryl substituents.

Brookhart and co-workers have recently designed two "sandwich" type naphthyl $\alpha$-diimine Ni-based precatalysts C21a (Fig. 12) containing two 8-p-tolylnaphthylimino moieties, which provided strong shielding in the Ni axial positions. ${ }^{92}$ These catalysts were shown to produce unique PEs with very high branching densities of up to 152 branches/1000 C and high molecular weights. Most importantly, some corresponding derivative nickel C21b (Fig. 12) was reported by Coates and co-workers and catalyzed higher $\alpha$-olefin polymerizations by precision chain walking with a preference for the $\omega, 1$-enchainment (Scheme 3). ${ }^{93}$ Relatively low branched poly ( $\alpha$-olefin)s that are highly "chain-straightened" semicrystalline $\left(T_{\mathrm{m}}>100{ }^{\circ} \mathrm{C}\right)$ were generated by these "sandwich" type catalysts. In addition, they also reported the synthesis of TPEs from the block copolymerization of 1-decene and ethylene using C21b. ${ }^{94}$ Polyolefin-based block copolymers with good crystallinity hard blocks were generated from 1-decene polymerization by high 2,1-insertion. Recently, Brookhart and co-workers have investigated some "sandwich"-type $\alpha$-diimine palladium catalysts C22 (Fig. 12) ${ }^{95}$ in ethylene polymerization. These catalysts were used to conduct living ethylene polymerization at $25{ }^{\circ} \mathrm{C}$ and produced hyperbranched PEs with narrow $M_{\mathrm{w}} / M_{\mathrm{n}}$ values (ca. 1.1). Comonomer incorporation of up to $14 \%$ was achieved in ethylene/methyl acrylate copolymerization.

Yuan and co-workers prepared some naphthyl- $\alpha$-diimine Ni-based catalysts C23a-d and C24 (Fig. 13) bearing different substituents (sec-phenethyl, methyl and $\mathrm{H}$ ) at the $o$-naphthyl position for ethylene polymerization. ${ }^{96}$ C23a yielded PEs with highly branched structures and up to $2.8 \times 10^{6} \mathrm{~g}$ PE (mol Ni h bar $)^{-1}\left(40{ }^{\circ} \mathrm{C}, 10 \mathrm{~min}\right)$ catalytic activities. Chen and co-workers also conducted higher $\alpha$-olefin polymerization using these nickel catalysts C23a-d to afford poly( $\alpha$-olefin)s with high molecular weight. ${ }^{97}$ The polymerization results showed the possibility of polymer structure control, via reaction temperatures, ligand structures, and the types and concentration of monomers. Specifically, increasing steric hindrance led to enhanced 2,1-insertion. Carfagna and co-workers synthesized some cationic palladium complexes C25a-c (Fig. 13) bearing $\alpha$-diimine ligands with fused aromatic rings, ${ }^{98}$ and studied their properties in the stereo-controlled copolymerization of CO with vinyl arene.

Sun and co-workers studied that some 2-benzhydrylnaphthyl-imino unsymmetrical nickel C26 (Fig. 14) catalyzed ethylene polymerization at high activities, ${ }^{99}$ and generated PEs with low branching densities of up to $12 / 1000 \mathrm{C}$ and high $T_{\mathrm{m}}$ (up to $131^{\circ} \mathrm{C}$ ). The corresponding difluorobenzhydryl substituents in C27 (Fig. 14) led to high activities and high polyethylene molecular weights. ${ }^{100}$

\subsection{Modifications of the $\alpha$-diimine backbone structures}

Compared with modifications of the $N$-aryl substituents, there have been far fewer studies related to the modifications of the $\alpha$-diimine backbone structures. Wu and co-workers designed two chiral $\alpha$-diimine based nickel catalysts $\mathbf{C 2 8 a}$ and $\mathbf{C 2 8 b}$ containing (1R)- and (1S)-camphyl backbones (Fig. 15) for olefin polymerization. ${ }^{101}$ Interestingly, the structure chirality had no obvious influence on the regioselectivity and catalytic activity. Living chain walking polymerization of 1-hexene and propylene in a wide range of temperatures was achieved. This camphyl type nickel catalyzed propylene homopolymerization at $-60{ }^{\circ} \mathrm{C}$ in $45 \%$ 1,3-enchainment fraction to produce polypropylene with an obvious melting point. Sun and co-workers explored some 4,5-bis(arylimino)pyrenylidene based dihalide nickel C29 (Fig. 15) which catalyzed ethylene polymerization with high activities of up to $4.4 \times 10^{6} \mathrm{~g} \mathrm{PE}(\mathrm{mol} \mathrm{Ni} \mathrm{h})^{-1}\left(40^{\circ} \mathrm{C}\right.$, $15 \mathrm{~min}) .^{102}$

Recently, Chen and co-workers have designed some $\mathrm{Ni}$ - and Pd-based $\alpha$-diimine precatalysts C30a-e (Fig. 16) possessing various groups on the acenaphthene-based backbone, ${ }^{103}$ which demonstrated activities of up to $1.6 \times 10^{7} \mathrm{~g}$ PE (mol Ni $\mathrm{h})^{-1}$ (20 $\left.{ }^{\circ} \mathrm{C}, 10 \mathrm{~min}\right)$, and yielded branched PEs with molecular weights of up to $4.2 \times 10^{5} \mathrm{~g} \mathrm{~mol}^{-1}$. The sterically bulky nickel complex C30e produced polymers with much lower branching density and higher $M_{\mathrm{n}}$ values than the other nickel complexes and the classic complex C30f. Significant effects of the backbone substituents were observed on related palladium catalyzed ethylene or E/MA (co)polymerizations. Once more, the palladium catalyst C30e produced a $\mathrm{PE}$ and E/MA copolymer with much higher $M_{\mathrm{n}}$ values than the rest of the palladium catalysts. Fu and co-workers also reported a similar $\alpha$-diimine nickel catalyst C31 (Fig. 16) for ethylene polymerization, which demonstrated higher thermal stability and higher catalytic activity than classic Brookhart-type $\alpha$-diimine catalyst C30f at elevated temperatures. ${ }^{104}$

Gao and He groups studied a family of three-dimensional geometry Ni- and Pd-based $\alpha$-diimine precatalysts C32 (Fig. 17) bearing a dibenzobarrelene backbone. ${ }^{105-108}$ The precision synthesis of functionalized polyolefins was achieved by Pdcatalyzed living coordination copolymerization of ethylene with various acrylate comonomers. ${ }^{105}$ In this system, the molecular weight, polydispersity, composition and branching topology of the E/MA copolymers can be tuned by changing ethylene pressure. These catalysts also showed high stability and high activity in NB polymerization and copolymerization with 
5-norbornene-2-carboxylic acid methyl ester when activated by $\mathrm{B}\left(\mathrm{C}_{6} \mathrm{~F}_{5}\right)_{3} \cdot{ }^{107,108}$ They also synthesized some similar nickel catalysts C33 (Fig. 17) containing a bulky bis( $\alpha$-diimine) ligand. ${ }^{109,110}$ These catalysts demonstrated high thermal stability and high catalytic activity toward NB polymerization. They also studied a related 6,13-dihydro-6,13-ethanopentacenebased nickel complex C34 (Fig. 17). ${ }^{111}$

\subsection{Dinuclear $\alpha$-diimine nickel and palladium catalysts}

A large number of dinuclear $\mathrm{Ni}$ and Pd complexes as catalyst precursors have been explored, and many of them have been applied for olefin polymerization and copolymerization reactions. ${ }^{112}$ However, only a limited number of Brookhart-type dinuclear $\mathrm{Ni}$ and $\mathrm{Pd}$ precatalysts ligated by $\alpha$-diimine were reporeted. ${ }^{113-116}$ For example, Revankar and co-workers developed a family of dinuclear Ni and Pd complexes (C35a and 35b, Fig. 18) with different groups at the ortho-position of aniline. ${ }^{113,114}$ These complexes efficiently oligomerized ethylene up to $10^{6} \mathrm{~g}$ oligomer ( $\left.\mathrm{mol} \mathrm{M} \mathrm{h} \mathrm{bar}\right)^{-1}$ high activities at $30^{\circ} \mathrm{C}$. In addition, dinuclear nickel complexes C35a exhibited high selectivity towards 1-butene polymerization. Sun and coworkers prepared a series of dinuclear nickel $\alpha$-diimine complexes (C36a-c, Fig. 18) with methylene bridged for ethylene polymerization. ${ }^{115}$ Zohuri and co-workers reported some bridged dinuclear nickel $\alpha$-diimine precatalysts C37a and C37b-f (Fig. 18) with alkyl- and 1,4-phenyl-linked based ligands. ${ }^{116,117}$ The ethylene polymerization results using $\mathbf{C 3 7 b}-\mathbf{f}$ suggested that these steric and electronic substituent effects of $\alpha$-diimine ligands have significant influences on polymerization behaviors. ${ }^{116} \mathbf{C 3 7 a}$ and $\mathbf{C 3 7 f}$ polymerized 1-hexene to obtain low to high molecular weight poly(1hexene) with $M_{\mathrm{w}}$ of up to $1.7 \times 10^{6} \mathrm{~g} \mathrm{~mol}^{-1} \cdot{ }^{117}$ The higher activities and lower level of branching densities were observed for C37f in comparison with C37a.

Chen and co-workers reported the synthesis of some binuclear nickel and palladium catalysts (C38a and 38b, Fig. 19) bearing conjugated $\alpha$-diimine ligands. ${ }^{118}$ Under similar conditions, C38a showed high activities of up to $1.05 \times 10^{6} \mathrm{~g}$ PE $(\mathrm{mol} \mathrm{Ni} \mathrm{h})^{-1}\left(2{ }^{\circ} \mathrm{C}, 30 \mathrm{~min}\right)$ in comparison with the corresponding mononuclear catalyst. Interestingly, two separate peaks were observed in the GPC curves of the PEs obtained by these palladium catalysts $\mathbf{C 3 8 b}$. Sun and co-workers also designed two dinuclear nickel catalysts (C39a and 39b, Fig. 19) supported by 4,5,9,10-tetra(arylimino)pyrenylidenes. ${ }^{119}$ These nickel catalysts demonstrated high stability and activities of $4.20 \times 10^{6} \mathrm{~g} \mathrm{PE}(\mathrm{mol} \mathrm{Ni} \mathrm{h})^{-1}\left(30{ }^{\circ} \mathrm{C}, 15 \mathrm{~min}\right)$ in ethylene polymerization, and produced relatively linear PEs (7-14 branches $/ 1000 \mathrm{C}$ ) with high $T_{\mathrm{m}}$ (up to $132^{\circ} \mathrm{C}$ ).

Chen and co-workers further synthesized some xanthene-, naphthalene- and biphenylene-bridged $\alpha$-diimine dinuclear nickel complexes $\mathbf{C 4 0}$ and $\mathbf{C 4 1}$ (Fig. 20) bearing different substituents and backbones. ${ }^{120,121}$ These dinuclear nickel complexes showed good thermal stability in the polymerization of ethylene and high catalytic activity of up to $10^{6} \mathrm{~g}$ PE (mol Ni h) ${ }^{-1}$. Interestingly, these Ni catalyst systems led to semicrystalline PEs with higher $M_{\mathrm{n}}$ values and relatively linear structures compared with their mononuclear analogues. The polymerization results indicated that the $\mathrm{Ni}-\mathrm{Ni}$ cooperativity effect invoked by these dinucleating ligands may be able to suppress the $\beta-\mathrm{H}$ elimination reaction and retard the process of chain walking. Interesting differences were observed by dinuclear palladium complexes C42 (Fig. 20) in ethylene (co)polymerizations versus their monomer nuclear analogue in terms of polymer $M_{\mathrm{n}}$ values and activity. ${ }^{121}$ In ethylene-methyl acrylate copolymerizations, the mononuclear palladium complex can incorporate appreciable amounts of comonomer, whereas $\mathbf{C 4 2}$ cannot incorporate any comonomer.

Takeuchi and co-workers developed two double-decker $\alpha$-diimine dinuclear catalysts C43a and C43b (Fig. 21) bearing a macrocyclic ligand. ${ }^{122-124}$ In ethylene polymerization, dinuclear complex $\mathbf{C 4 3 b}$ displayed higher activity compared with the corresponding mononuclear catalyst and C43a. The polyethylenes obtained by $\mathbf{C 4 3 a}$ and $\mathbf{C 4 3} \mathbf{b}$ were less branched than those made with a mononuclear one. $\mathbf{C 4 3} \mathbf{a}$ and $\mathbf{C 4 3} \mathbf{b}$ catalyzed copolymerization to afford branched E-MA copolymers containing some acrylate units incorporated on the polymer backbone. ${ }^{122}$ The polymerization of $\alpha$-olefins by $\mathbf{C 4 3 b}$ occurred with high selectivity "chain-straightened" in a $\omega, 1$-enchainment $(>80 \%$, Scheme 3$)$ and generated high-linearity solid polymers, ${ }^{123}$ while the mononuclear analogues produced oily oligomers as a result of low selectivity in 1,2- or 2,1-insertion. In addition, C43b catalyzed copolymerization of $\mathrm{E}$ with acrylic anhydride to afford the copolymer containing the repeating unit from acrylic anhydride. ${ }^{124}$ These studies clearly indicated that structures of $\alpha$-diimine ligands can strongly influence the polymerization processes.

\section{Copolymerizations of olefins with polar monomers}

In the process of exploring various Brookhart catalysts, various olefinic monomers have been polymerized and copolymerized. ${ }^{27,31,125-127}$ The applicable monomers have also been rapidly growing to include linear ${ }^{128,129}$ and branched $^{130,131} \quad \alpha$-olefins, cycloalkyl substituted $\alpha$-olefins, ${ }^{132-136}$ cycloolefins, ${ }^{137}$ dienes, ${ }^{138}$ trienes, ${ }^{139,140}$ internal olefins, ${ }^{141-144}$ norbonene type monomers, ${ }^{101-104}$ and different polar comonomers. ${ }^{3,27,28}$ It should be noted that the continuous interest in Brookhart-type catalysts largely originates from their capabilities in copolymerizations of olefins with polar functionalized comonomers. The introduction of some polar functional substituents into polyolefins can significantly improve their properties and broaden their applications. Concerning industrially relevant polar comonomers, or the so called fundamental polar monomers, $\alpha$-diimine palladium catalysts only worked for acrylates, vinyl ketones, silyl vinyl ethers, etc. ${ }^{145-147} \mathrm{~A}$ lot of specially designed polar monomers, ${ }^{27,28}$ such as the ones bearing long spacers between the double bond and acrylate group, are also suitable polar comonomers. However, many other fundamental polar monomers (such as vinyl ether, vinyl acetate, vinyl halide, acrylo- 
nitrile, styrene, etc.) completely shut down ethylene polymerization due to various reasons, such as cationic polymerization, $\beta$-X elimination, and/or formation of a stable metal chelate. ${ }^{148-150}$ The expansion of the polar monomer substrate scope through catalyst improvements represents a major challenge in this field. Compared with palladium, nickel is much more oxophillic and less tolerant towards polar monomers. In the presence of large amounts of cocatalysts or additives, and under harsh conditions, $\alpha$-diimine nickel catalysts were demonstrated to copolymerize ethylene with methyl acrylate. ${ }^{151}$ The utilization of low-cost nickel $\alpha$-diimine catalysts to address the polar monomer problem represents another fascinating challenge in this field.

Chen and co-workers showed that ortho-dibenzhydryl-based palladium catalysts $\mathbf{C} 3$ led to the formation of semicrystalline E/MA copolymers with $M_{\mathrm{n}}$ of up to $1.9 \times 10^{4} \mathrm{~g} \mathrm{~mol}^{-1},^{60}$ and low branching density (25/1000 C). The sterically bulky catalysts C3 mediated efficient copolymerization of ethylene with acrylate or acrylic comonomers (Group B, Scheme 4) with relatively linear microstructures (as low as 9/1000 C) and high melting temperatures $\left(T_{\mathrm{m}}\right.$ close to $\left.120{ }^{\circ} \mathrm{C}\right)$. These "slow chain walking" palladium catalysts still cannot copolymerize ethylene with many fundamental polar monomers (Group A, Scheme 4). However, with some $\mathrm{CH}_{2}$ spacers between the polar groups and the double bond, the polar monomers of group $\mathbf{C}$ are suitable comonomers for catalysts $\mathbf{C 4 a} .{ }^{61}$ Notably, the conventional Brookhart $\alpha$-diimine palladium catalysts will undergo fast chain walking, which brings the metal center close to the polar groups and the subsequent termination reactions will completely shut down copolymerizations. The slow chain walking feature of $\mathbf{C 4}$ is the key factor for the successful expansion of the polar monomer substrate scope.

During the above-mentioned copolymerization studies, it was found that polar monomers of group D (Scheme 4) quenched the C4a mediated ethylene polymerization. ${ }^{61}$ Although the chain walking process is efficiently slowed down, the occasional chain walking can still bring the metal center close to the $\mathrm{Cl} / \mathrm{OH}$ groups and induce termination reactions. Strategies to address this issue are currently being explored in order to further expand the polar monomer substrate scope. Recently, Chen and co-workers have designed a family of $\mathrm{Ni}$ and Pd $\alpha$-diimine complexes C44a-d (Fig. 22) with nitrogencontaining second coordination spheres. ${ }^{152}$ For the nickel catalysts, PEs with highly linear structures (branching $<1 / 1000 \mathrm{C}$ )

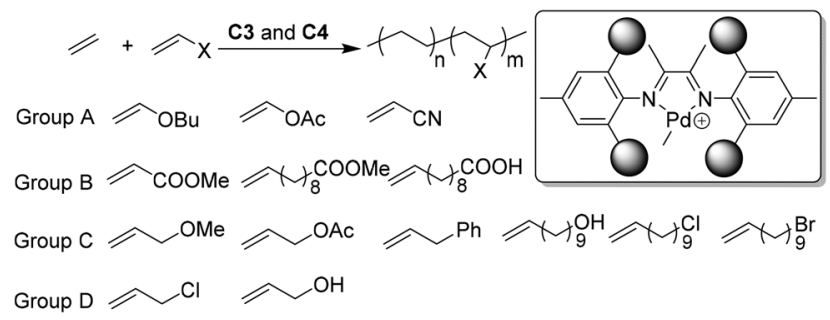

Scheme 4 Direct synthesis of polar functionalized semicrystalline copolymers using slow chain walking palladium catalysts. ${ }^{60,61}$

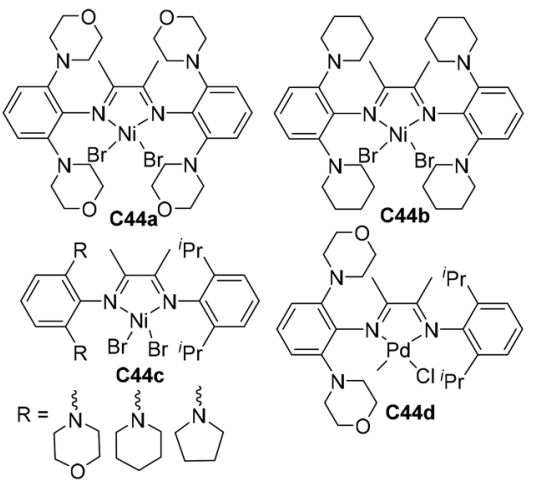

Fig. 22 Structures of $\mathrm{Ni}$ and $\mathrm{Pd} \alpha$-diimine catalysts bearing nitrogencontaining second coordination spheres. ${ }^{152}$

and high $T_{\mathrm{m}}\left(>130^{\circ} \mathrm{C}\right)$ were obtained. For the palladium catalyst C44d, polyethylenes with moderately branched structures (ca. 70/1000 C) were generated. This suggested that the chain walking tendency of C44d is lower than that of classic Brookhart $\alpha$-diimine palladium catalysts ( $c a .100 / 1000$ C), but much higher than that of the previously reported "slow chain walking" catalysts (C2 and C3, 6-25/1000 C). However, C44d can mediate efficient ethylene copolymerizations with the group D polar comonomers. Control experiments and computational results revealed the critical roles of the metal-nitrogen interactions in these (co)polymerization reactions.

Jordan and co-workers developed some amide-functionalized $\alpha$-diimine palladium catalysts C45a-d (Fig. 23) containing $-\mathrm{CONHMe}$ or $-\mathrm{CONMe}_{2}$ groups on the $N$-phenyl rings. ${ }^{153} \mathrm{In}$ ethylene polymerization, ${ }^{\mathrm{i}} \mathrm{Pr}$-substituted $\mathbf{C 4 5 c}$ and $\mathbf{C 4 5 d}$ showed a higher activity of $10^{7} \mathrm{~g}$ PE $(\mathrm{mol} \mathrm{Ni} \mathrm{h})^{-1}$ than C45a and $\mathbf{C 4 5 b}$ with ortho-dibenzhydryl groups, and yielded branched (77-81 branches/1000 C) PEs with $M_{\mathrm{n}}$ values in the range of $2.6-60 \times 10^{4} \mathrm{~g} \mathrm{~mol}^{-1}$. In ethylene copolymerization, the incorporated levels of MA (Scheme 5) and acrylic acid (AA) using C45a were higher than $\mathbf{4 5 b}$ and ${ }^{\mathrm{i}} \mathrm{Pr}$-substituted C8a.

Kaminsky and co-workers first investigated the E-NB copolymerization studies using classic Brookhart-type palladium catalysts, ${ }^{154}$ which displayed significantly higher NB incorporation ability than metallocene catalysts. ${ }^{155}$ Clearly, $\alpha$-diimine palladium catalysts possess great reactivity towards norbornene monomers and great tolerance towards the ester type polar groups. However, the reactivity of $\alpha$-diimine palladium catalysts towards polar functionalized norbornene monomers has not been explored over a very long period of time.

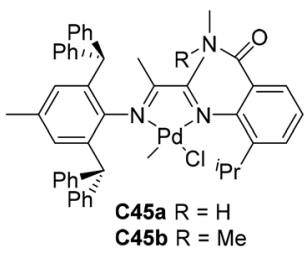

vs

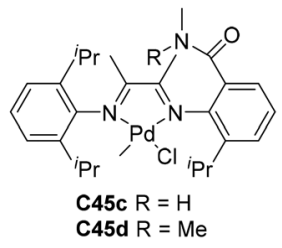

Fig. 23 Amide-functionalized $\alpha$-diimine Pd catalysts. ${ }^{153}$ 


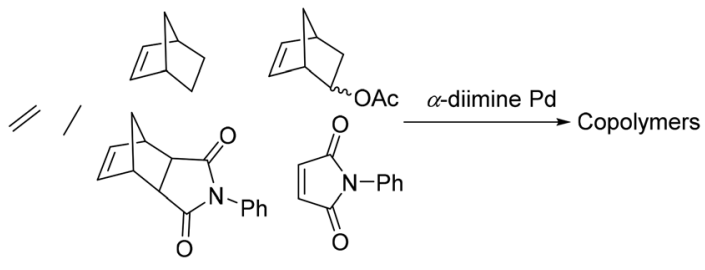

Scheme 5 Copolymerizations of ethylene and norbornene derivatives or some nitrogen-containing monomers. ${ }^{81}$

Only recently, Chen and co-workers have studied the ethylene copolymerizations with a family of polar functionalized norbornene type comonomers or nitrogen-containing monomers (NB-NP, NB-OAc and NP, Scheme 5) using paramethoxy substituted $\alpha$-diimine palladium catalyst C13a. ${ }^{156}$ Branched high molecular weight copolymers (55-89/1000 C; $M_{\mathrm{n}}$ up to 125000 ) with good comonomer incorporations (1.1-9.1\%) were obtained. In addition, the same group reported the properties of $\mathbf{C 1 5}$ (Fig. 8) in ethylene copolymerizations with NB and NB-Ac (Scheme 5). ${ }^{81}$ The phenyl-substituted catalyst showed much higher activity, and produced a much higher $M_{\mathrm{n}}$ (up to 132500 ) copolymer with slightly lower NB $(14 \%)$ and NB-Ac (1.67\%) incorporation ratios than the rest of the catalysts.

Acrylic acid (AA) is a quite challenging polar monomer to be incorporated during olefin polymerization, due to the presence of both oxygen and hydroxyl polar groups. Successful copolymerizations have been achieved using phosphine-sulfonate palladium catalysts. ${ }^{157-159}$ Recently, Chen and co-workers have investigated the copolymerization of 1-octene with AA (Scheme 6$)^{160}$ catalyzed by sterically bulky $\alpha$-diimine palladium catalysts (C4a and C8a-c, Fig. 2 and 4), producing branched copolymers (58-98/1000 C) with high comonomer incorporation (1.07-15.7\%) and high $M_{\mathrm{n}}$ values of up to 40400 . This copolymerization behavior provides an alternative strategy to prepare carboxylic acid functionalized branched polyolefins.

Recently, a major breakthrough in polar monomer substrate scope expansion has been achieved by Brookhart and coworkers (Scheme 7). ${ }^{161,162}$ They studied $\alpha$-diimine Pd-catalyzed ethylene copolymerization of vinyltrialkoxysilanes (VTEoS) to afford copolymers with highly branched structures (ca. 100 branches/1000 C) and low molecular weights. ${ }^{161}$ Incorporation ratios from 0.25 to $2.0 \mathrm{~mol} \%$ were generated with little rate retardation relative to ethylene polymerization. Compared with traditional catalytic systems, the sandwich-type catalyst produced polar functionalized copolymers with higher $M_{\mathrm{n}}$ values

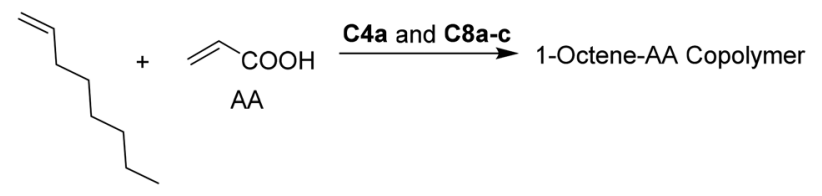

Scheme 6 Copolymerization of 1-octene with acrylic acid catalyzed by $\alpha$-diimine Pd catalysts. ${ }^{160}$

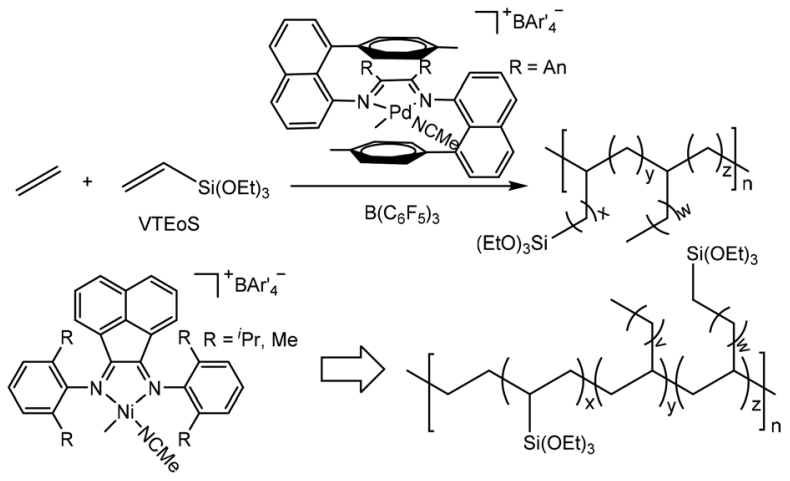

Scheme 7 Cationic $\alpha$-diimine-based Pd- and Ni-catalyzed ethylene copolymerization with vinyltrialkoxysilanes. ${ }^{161,162}$

and narrow $M_{\mathrm{w}} / M_{\mathrm{n}}$ values of 1.2-1.4. More importantly, multiple trialkoxysilyl groups can be incorporated per polymer chain.

There have also been some recent advances in $\alpha$-diimine Ni-catalyzed ethylene copolymerization with polar monomers. For instance, Brookhart and co-workers achieved copolymerization of ethylene with VTEOS (Scheme 7) using cationic $(\alpha$-diimine $) \mathrm{NiMe}\left(\mathrm{CH}_{3} \mathrm{CN}\right)^{+}$catalysts $/ \mathrm{B}\left(\mathrm{C}_{6} \mathrm{~F}_{5}\right)_{3}$ at $60{ }^{\circ} \mathrm{C}$ to give variously branched (5-60 branches/1000 C) copolymers with high molecular weights. ${ }^{162}$ Incorporation ratios ranging between 0.23 and 10.0 mol\% with multiple $-\mathrm{Si}(\mathrm{OEt})_{3}$ groups incorporated per polymer chain were achieved.

Recently, Chen and co-workers have reported the preparation of silicon-functionalized polyolefin materials through subsequent dehydrogenative silylation catalysed by the pyridine-diimine cobalt catalyst and ethylene copolymerization using the classic $\alpha$-diimine nickel catalyst (Scheme $8(\mathrm{I})$ ). ${ }^{163}$ The allylsilanes with both the silanes functional groups and internal double bond were first prepared from dehydrogenative silylations of different terminal olefins and alkylsilanes using a pyridine-diimine cobalt-catalyst. ${ }^{164}$ Subsequently, an $\alpha$-diimine traditional nickel catalyst $\left[\left(2,4,6-\mathrm{Me}_{3} \mathrm{C}_{6} \mathrm{H}_{2}\right) \mathrm{N}=\mathrm{C}\right.$ $(\mathrm{Me})]_{2} \mathrm{NiBr}_{2}$ can mediate efficient ethylene copolymerizations with these allylsilanes to produce silicon-functionalized polyolefins. This provides an alternative strategy to utilize inexpensive and widely available starting materials such as

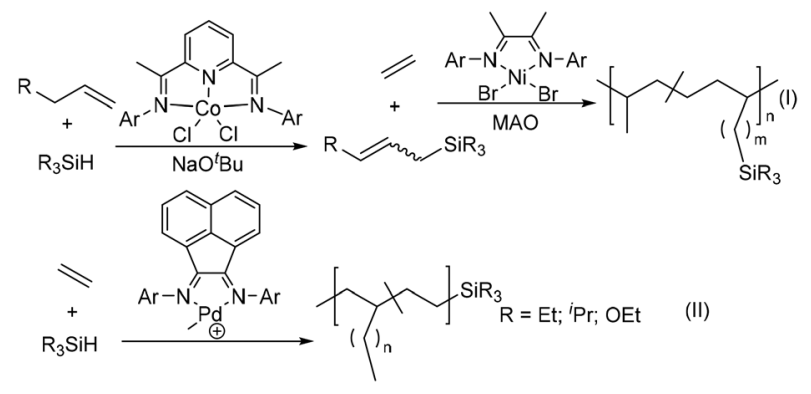

Scheme 8 Preparation of polyolefins containing silicon-functionalities by ethylene (co)polymerization. ${ }^{163-165}$ 

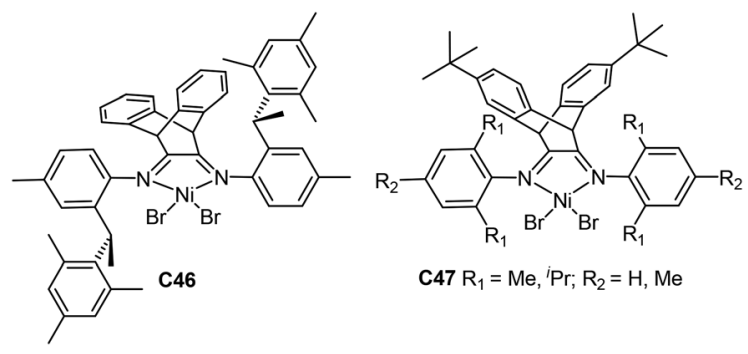

Fig. 24 Dibenzobarrelene-bridged $\alpha$-diimine nickel complexes. ${ }^{166-169}$

olefins and silanes. Guironnet and co-workers demonstrated that the synthesis of semitelechelic polyethylene via the cationic $\alpha$-diimine Pd-catalyzed chain-transfer ethylene (co) polymerization by various silanes as chain-transfer agents (Scheme 8(II)). ${ }^{165}$ The polymer end-group structure and molecular weight were effectively tuned via varying the types of silanes and their concentration.

Coates and co-workers prepared a chiral sec-phenethyl based $\alpha$-diimine nickel catalyst $\mathbf{C 4 6}$ (Fig. 24) containing a dibenzobarrelene-bridged backbone, ${ }^{166}$ which showed great properties in ethylene polymerization. The catalyst system yielded highly linear PEs with higher $M_{\mathrm{n}}$ values and narrow $M_{\mathrm{w}} / M_{\mathrm{n}}$ values. Catalyst $\mathbf{C 4 6}$ showed living polymerization behavior at room temperature and generated $\mathrm{PE}$ with high $T_{\mathrm{m}}$ of up to $135^{\circ} \mathrm{C}$ and a highly linear structure at $-20^{\circ} \mathrm{C}$. Besides, copolymerization of ethylene with methyl 10-undecenoate (Scheme 4) was realized to afford high molecular weight (up to $1.05 \times 10^{5} \mathrm{~g} \mathrm{~mol}^{-1}$ ) ester-functionalized copolymers with very low branching densities.

$\mathrm{Wu}$ and co-workers also demonstrated that a family of dibenzobarrelene-bridged $\alpha$-diimine nickel C47 (Fig. 24) catalysed ethylene polymerization with activities of up to $10^{7} \mathrm{~g} \mathrm{PE}$ $(\mathrm{mol} \mathrm{Ni} \mathrm{h})^{-1}{ }^{167}$ The bulky ligand backbone led to high thermal stability and improved tolerance towards polar groups. These catalysts were stable at temperatures of up to $100{ }^{\circ} \mathrm{C}$. Moreover, ethylene copolymerization with methyl 10-undecenoate was conducted in a living manner (Scheme 4). Conley and co-workers prepared some sulfated zirconia supported $\alpha$-diimine nickel catalysts and applied them in ethylene copolymerization with methyl 10-undecenoate. ${ }^{168}$ Plenio and co-workers designed some bowl-shaped diimine nickel catalysts with two pentiptycenyl-substituents, and studied their properties in ethylene copolymerization with various comonomers including methyl 10-undecenoate. ${ }^{169}$

\section{Conclusion and outlook}

The Brookhart-type nickel and palladium complexes ligated by $\alpha$-diimine have attracted considerable attention for olefin polymerization during the past two decades. Their catalytic properties are strongly influenced by ligand structures as well as polymerization conditions (temperature, types and concentration of monomers), which subsequently effectively influence the properties of the resulting polymers and copolymers. Most importantly, their chain walking capabilities provide great potential for the control of polymer microstructures.

In this review, we first briefly discussed the chain walking mechanism of Brookhart-type catalysts in ethylene polymerization and $\alpha$-olefin polymerization. Subsequently, some recent advances in catalyst developments were summarized. Specifically, the modifications of $\mathrm{N}$-aryl substituents and of the ligand backbone structure, as well as the utilization of dinucleating ligands, were described. Finally, the applications of some of the newly developed $\alpha$-diimine Ni and Pd catalysts in olefin copolymerizations with polar comonomers were demonstrated. Special attention was paid to the examples where a new polar comonomer substrate scope was enabled through the utilization of new catalysts. The Brookhart-type Ni and Pd catalysts ligated by $\alpha$-diimine are easy to synthesize, extremely versatile, tolerant towards various functional groups, and capable of generating numerous polymer microstructures that are difficult to access otherwise. Because of these superior and unique properties, they continue to be of great research interest even after twenty years of extensive research. It is believed that this research enthusiasm will continue, and we will see more novel catalysts as well as novel polyolefin materials.

\section{Conflicts of interest}

There are no conflicts to declare.

\section{Acknowledgements}

This work was supported by the National Natural Science Foundation of China (NSFC, 21690071 and 21801002) and the Fundamental Research Funds for the Central Universities.

\section{Notes and references}

1 D. B. Malpass, Introduction to Industrial Polyethylene, Wiley, Hoboken, NJ, USA, 2010, pp. 85-97.

2 A. Nakamura, S. Ito and K. Nozaki, Chem. Rev., 2009, 109, 5215-5244.

3 Z. Chen and M. Brookhart, Acc. Chem. Res., 2018, 51, 1831-1839.

4 L. K. Johnson, C. M. Killian and M. Brookhart, J. Am. Chem. Soc., 1995, 117, 6414-6415.

5 L. K. Johnson, S. Mecking and M. Brookhart, J. Am. Chem. Soc., 1996, 118, 267-268.

6 S. D. Ittel, L. K. Johnson and M. Brookhart, Chem. Rev., 2000, 100, 1169-1204.

7 Z. Dong and Z. Ye, Polym. Chem., 2012, 3, 286-301.

8 L. H. Guo, S. Y. Dai, X. L. Sui and C. L. Chen, ACS Catal., 2016, 6, 428-441.

9 Z. Jian, L. Falivene, G. Boffa, S. O. Sánchez, L. Caporaso, A. Grassi and S. Mecking, Angew. Chem., Int. Ed., 2016, 55, 14378-14383. 
10 M. Chen and C. L. Chen, ACS Catal., 2017, 7, 1308-1312.

11 G. Song, W. M. Pang, W. Li, M. Chen and C. L. Chen, Polym. Chem., 2017, 8, 7400-7405.

12 B. P. Yang, S. Y. Xiong and C. L. Chen, Polym. Chem., 2017, 8, 6272-6276.

13 J. X. Gao, W. Cai, Y. Hu and C. L. Chen, Polym. Chem., 2019, 10, 1416-1422.

14 S. Ito, Bull. Chem. Soc. Jpn., 2018, 91, 251-261.

15 Z. Cai and L. H. Do, Organometallics, 2018, 37, 38743882 .

16 W. Zhang, P. M. Waddell, M. A. Tiedemann, C. E. Padilla, J. J. Mei, L. Y. Chen and B. P. Carrow, J. Am. Chem. Soc., 2018, 140, 8841-8850.

17 Y. Mitsushige, H. Yasuda, B. Carrow, S. Ito, M. Kobayashi, T. Tayano, Y. Watanabe, Y. Okuno, S. Hayashi, J. Kuroda, Y. Okumura and K. Nozaki, ACS Macro Lett., 2018, 7, 305311.

18 X. Wang and K. Nozaki, J. Am. Chem. Soc., 2018, 140, 15635-15640.

19 T. Liang and C. L. Chen, Inorg. Chem., 2018, 57, 1491314919.

20 M. Chen and C. L. Chen, Angew. Chem., Int. Ed., 2018, 57, 3094-3098.

21 J. X. Gao, B. P. Yang and C. L. Chen, J. Catal., 2019, 369, 233-238.

22 Z. Guan and C. S. Popeney, Top. Organomet. Chem., 2009, 2, 179-220.

23 C. Tan and C. L. Chen, Angew. Chem., Int. Ed., 2019, 58, DOI: 10.1002/anie.201814634.

24 J. M. Kaiser and B. K. Long, Coord. Chem. Rev., 2018, 372, 141-152.

25 L. H. Guo and C. L. Chen, Sci. China: Chem., 2015, 58, 1663-1673.

26 Y. S. Chen, L. Wang, H. J. Yu, Y. L. Zhao, R. L. Sun, G. H. Jing, J. Huang, H. Khalid, N. M. Abbasi and M. Akram, Prog. Polym. Sci., 2015, 45, 23-43.

27 C. L. Chen, ACS Catal., 2018, 8, 5506-5514.

28 L. H. Guo, W. Liu and C. L. Chen, Mater. Chem. Front., 2017, 1, 2487-2494.

29 D. Takeuchi, Polym. J., 2018, 50, 573-578.

30 H. Suo, G. A. Solan, Y. Ma and W. H. Sun, Coord. Chem. Rev., 2018, 372, 101-106.

31 C. L. Chen, Nat. Rev. Chem., 2018, 2, 6-14.

32 J. Wang, L. Wang, H. Yu, R. S. Ullah, M. Haroon, Z. Abdin, X. Xia and R. U. Khan, Eur. J. Inorg. Chem., 2018, 14501468.

33 N. E. Mitchell and B. K. Long, Polym. Int., 2019, 68, 1426.

34 V. M. Mohring and G. Fink, Angew. Chem., Int. Ed. Engl., 1985, 24, 1001-1003.

35 G. J. Domski, J. M. Rose, G. W. Coates, A. D. Bolig and M. Brookhart, Prog. Polym. Sci., 2007, 32, 30-92.

36 L. Pei, F. Liu, H. Liao, J. Gao, L. Zhong, H. Gao and Q. Wu, ACS Catal., 2018, 8, 1104-1113.

37 Z. Guan, P. M. Cotts, E. F. McCord and S. J. McLain, Science, 1999, 283, 2059-2062.
38 D. P. Gates, S. A. Svejda, E. Oñate, C. M. Killian, L. K. Johnson, P. S. White and M. Brookhart, Macromolecules, 2000, 33, 2320-2334.

39 F. S. Liu, H. B. Hu, Y. Xu, L. H. Guo, S. B. Zai, K. M. Song, H. Y. Gao, L. Zhang, F. M. Zhu and Q. Wu, Macromolecules, 2009, 42, 789-7796.

40 C. S. Popeney and Z. Guan, Organometallics, 2005, 24, 1145-1155.

41 C. S. Popeney and Z. Guan, Macromolecules, 2010, 43, 4091-4097.

42 J. Y. Liu, Y. G. Li, Y. S. Li and N. H. Hu, J. Appl. Polym. Sci., 2008, 109, 700-707.

43 C. S. Popeney, C. M. Levins and Z. Guan, Organometallics, 2011, 30, 2432-2452.

44 Z. Guan, J. Polym. Sci., Part A: Polym. Chem., 2003, 41, 3680-3692.

45 J. M. Kaiser, W. C. Anderson Jr. and B. K. Long, Polym. Chem., 2018, 9, 1567-1570.

46 K. S. O’Connor, J. R. Lamb, T. Vaidya, I. Keresztes, K. Klimovica, A. M. LaPointe, O. Daugulis and G. W. Coates, Macromolecules, 2017, 50, 7010-7027.

47 I. Pierro, G. Zanchin, E. Parisini, J. Martí-Rujas, M. Canetti, G. Ricci, F. Bertini and G. Leone, Macromolecules, 2018, 51, 801-814.

48 E. F. McCord, S. J. McLain, L. T. J. Nelson, S. D. Ittel, D. Tempel, C. M. Killian, L. K. Johnson and M. Brookhart, Macromolecules, 2007, 40, 410-420.

49 G. J. Domski, J. M. Rose, G. W. Coates, A. D. Bolig and M. Brookhart, Prog. Polym. Sci., 2007, 32, 30-92.

50 A. E. Cherian, J. M. Rose, E. B. Lobkovsky and G. W. Coates, J. Am. Chem. Soc., 2005, 127, 13770-13771.

51 J. M. Rose, A. E. Cherian and G. W. Coates, J. Am. Chem. Soc., 2006, 128, 4186-4187.

52 D. N. Vaccarello, K. S. O'Connor, P. Iacono, J. M. Rose, A. E. Cherian and G. W. Coates, J. Am. Chem. Soc., 2018, 140, 6208-6211.

53 D. H. Camacho, E. V. Salo, J. W. Ziller and Z. Guan, Angew. Chem., Int. Ed., 2004, 43, 1821-1825.

54 D. H. Camacho and Z. Guan, Macromolecules, 2005, 38, 2544-2546.

55 C. S. Popeney, D. H. Camacho and Z. Guan, J. Am. Chem. Soc., 2007, 129, 10062-10063.

56 C. S. Popeney, C. M. Levins and Z. Guan, Organometallics, 2011, 30, 2432-2452.

57 J. L. Rhinehart, L. A. Brown and B. K. Long, J. Am. Chem. Soc., 2013, 135, 16316-16319.

58 J. L. Rhinehart, N. E. Mitchell and B. K. Long, ACS Catal., 2014, 4, 2501-2504.

59 L. A. Brown, W. C. J. Anderson, N. E. Mitchell, K. R. Gmernicki and B. K. Long, Polymers, 2018, 10, 41.

60 S. Y. Dai, X. L. Sui and C. L. Chen, Angew. Chem., Int. Ed., 2015, 54, 9948-9953.

61 S. Y. Dai and C. L. Chen, Angew. Chem., Int. Ed., 2016, 55, 13281-13285.

62 Y. N. Na, S. Y. Dai and C. L. Chen, Macromolecules, 2018, 51, 4040-4048. 
63 L. H. Guo, S. Y. Dai and C. L. Chen, Polymers, 2016, 8, 37.

64 L. H. Guo, K. Lian, W. Kong, S. Xu, G. Jiang and S. Y. Dai, Organometallics, 2018, 37, 2442-2449.

65 S. Y. Dai, S. X. Zhou, W. Zhang and C. L. Chen, Macromolecules, 2016, 49, 8855-8862.

66 J. L. Sun, F. Z. Wang, W. M. Li and M. Chen, RSC Adv., 2017, 7, 55051-55059.

67 S. Y. Dai and C. L. Chen, Macromolecules, 2018, 51, 68186824.

68 X. X. Wang, L. L. Fan, Y. C. Yuan, S. Z. Du, Y. Sun, G. A. Solan, C. Y. Guo and W. H. Sun, Dalton Trans., 2016, 45, 18313-18323.

69 L. L. Fan, E. Yue, S. Z. Du, C. Y. Guo, X. Hao and W. H. Sun, RSC Adv., 2015, 5, 93274-93282.

70 L. L. Fan, S. Z. Du, C. Y. Guo, X. Hao and W. H. Sun, J. Polym. Sci., Part A: Polym. Chem., 2015, 53, 13691378.

71 S. Z. Du, Q. F. Xing, Z. Flisak, E. Yue, Y. Sun and W. H. Sun, Dalton Trans., 2015, 44, 12282-12291.

72 S. Z. Du, S. L. Kong, Q. S. Shi, J. Mao, C. Y. Guo, J. J. Yi, T. L. Liang and W. H. Sun, Organometallics, 2015, 34, 582590.

73 X. X. Wang, L. L. Fan, Y. P. Ma, C. Y. Guo, G. A. Solan, Y. Sun and W. H. Sun, Polym. Chem., 2017, 8, 27852795.

74 H. Y. Suo, I. V. Oleynik, C. B. Huang, I. I. Oleynik, G. A. Solan, Y. P. Ma, T. L. Liang and W. H. Sun, Dalton Trans., 2017, 46, 15684-15697.

75 Y. N. Zeng, Q. Mahmood, Q. Y. Zhang, T. L. Liang and W. H. Sun, J. Polym. Sci., Part A: Polym. Chem., 2018, 56, 922-930.

76 F. Zhai and R. F. Jordan, Organometallics, 2017, 36, $2784-$ 2799.

77 X. L. Sui, C. W. Hong, W. M. Pang and C. L. Chen, Mater. Chem. Front., 2017, 1, 967-972.

78 J. Fang, X. L. Sui, Y. G. Li and C. L. Chen, Polym. Chem., 2018, 9, 4143-4149.

79 S. Du, Q. Xing, Z. Flisak, E. Yue, Y. Sun and W. H. Sun, Dalton Trans., 2015, 44, 12282-12291.

80 Y. Chen, S. Du, C. Huang, G. A. Solan, X. Hao and W. H. Sun, J. Polym. Sci., Part A: Polym. Chem., 2017, 55, 1971-1983.

81 R. K. Wang, M. H. Zhao and C. L. Chen, Polym. Chem., 2016, 7, 3933-3938.

82 K. Lian, Y. Zhu, W. Li, S. Y. Dai and C. L. Chen, Macromolecules, 2017, 50, 6074-6080.

83 M. H. Zhao and C. L. Chen, ACS Catal., 2017, 7, 74907494.

84 M. Chen, B. P. Yang and C. L. Chen, Angew. Chem., Int. Ed., 2015, 54, 15520-15524.

85 W. C. Anderson Jr., J. L. Rhinehart, A. G. Tennyson and B. K. Long, J. Am. Chem. Soc., 2016, 138, 774-777.

86 W. C. Anderson Jr., S. H. Park, L. A. Brown, J. M. Kaiser and B. K. Long, Inorg. Chem. Front., 2017, 4, 1108-1112.

87 W. P. Zou, W. M. Pang and C. L. Chen, Inorg. Chem. Front., 2017, 4, 795-800.
88 V. Rosar, A. Meduri, T. Montini, P. Fornasiero, E. Zangrando and B. Milani, Dalton Trans., 2018, 47, 2778-2790.

89 S. Ahmadjo, S. Damavandi, G. H. Zohuri, A. Farhadipour, N. Samadieh and Z. Etemadinia, J. Organomet. Chem., 2017, 835, 43-51.

90 S. Ahmadjo, S. Damavandi, G. H. Zohuri, A. Farhadipour, N. Samadieh and Z. Etemadinia, Polym. Bull., 2017, 74, 3819-3832.

91 R. Mundil, A. Sokolohorskyj, J. Hošek, J. Cvačka, I. Císařová, J. Kvíčala and J. Merna, Polym. Chem., 2018, 9, 1234-1248.

92 D. Zhang, E. T. Nadres, M. Brookhart and O. Daugulis, Organometallics, 2013, 32, 5136-5143.

93 T. Vaidya, K. Klimovica, A. M. LaPointe, I. Keresztes, E. B. Lobkovsky, O. Daugulis and G. W. Coates, J. Am. Chem. Soc., 2014, 136, 7213-7216.

94 K. S. O'Connor, A. Watts, T. Vaidya, A. M. LaPointe, M. A. Hillmyer and G. W. Coates, Macromolecules, 2016, 49, 6743-6751.

95 K. E. Allen, J. Campos, O. Daugulis and M. Brookhart, ACS Catal., 2015, 5, 456-464.

96 J. C. Yuan, F. Z. Wang, W. B. Xu, T. J. Mei, J. Li, B. N. Yuan, F. Y. Song and Z. Jia, Organometallics, 2013, 32, 3960-3968.

97 F. Z. Wang, S. S. Tian, R. P. Li, W. M. Li and C. L. Chen, Chin. J. Polym. Sci., 2018, 36, 157-162.

98 C. Carfagna, G. Gatti, P. Paoli, B. Binotti, F. Fini, A. Passeri, P. Rossi and B. Gabriele, Organometallics, 2014, 33, 129-144.

99 C. Wen, S. Yuan, Q. Shi, E. Yue, D. Liu and W. H. Sun, Organometallics, 2014, 33, 7223-7231.

100 S. Yuan, E. Yue, C. Wen and W. H. Sun, RSC Adv., 2016, 6, 7431-7438.

101 J. Liu, D. R. Chen, H. Wu, Z. F. Xiao, H. Y. Gao, F. M. Zhu and Q. Wu, Macromolecules, 2014, 47, 3325-3331.

102 K. Song, W. Yang, B. Li, Q. Liu, C. Redshaw, Y. Li and W. H. Sun, Dalton Trans., 2013, 42, 9166-9175.

103 W. Zou and C. Chen, Organometallics, 2016, 35, 17941801.

104 L. Zhu, D. Zang, Y. Wang, Y. Guo, B. Jiang, F. He, Z. Fu, Z. Fan, M. A. Hickner, Z. K. Liu and L. Q. Chen, Organometallics, 2017, 36, 1196-1203.

105 S. Zhong, Y. Tan, L. Zhong, J. Gao, H. Liao, L. Jiang, H. Gao and Q. Wu, Macromolecules, 2017, 50, 5661-5669.

106 Z. Xiao, H. Zheng, C. Du, L. Zhong, H. Liao, J. Gao, H. Gao and Q. Wu, Macromolecules, 2018, 51, 9110-9121.

107 P. Huo, W. Y. Liu, X. H. He, H. M. Wang and Y. W. Chen, Organometallics, 2013, 32, 2291-2299.

108 P. Huo, W. Y. Liu, X. H. He, Z. Wei and Y. W. Chen, Polym. Chem., 2014, 5, 1210-1218.

109 X. H. He, Y. J. Deng, Z. L. Han, Y. Yang and D. F. Chen, J. Polym. Sci., Part A: Polym. Chem., 2016, 54, 3495-3505.

110 X. H. He, Y. J. Deng, X. Jiang, Z. J. Wang, Y. P. Yang, Z. L. Hana and D. F. Chen, Polym. Chem., 2017, 8, 23902396. 
111 P. Huo, J. B. Li, W. Y. Liu, G. Q. Mei and X. H. He, RSC Adv., 2017, 7, 51858-51863.

112 M. Delferro and T. J. Marks, Chem. Rev., 2011, 111, 24502485.

113 S. P. Netalkar, P. P. Netalkar, M. P. Sathisha, S. Budagumpi and V. K. Revankar, Catal. Lett., 2014, 144, 181-191.

114 S. P. Netalkar, S. Budagumpi, H. H. Abdallah, P. P. Netalkar and V. K. Revankar, J. Mol. Struct., 2014, 1075, 559-565.

115 S. Kong, K. Song, T. Liang, C. Y. Guo, W. H. Sun and C. Redshaw, Dalton Trans., 2013, 42, 9176-9187.

116 M. Khoshsefat, G. H. Zohuri, N. Ramezanian, S. Ahmadjo and M. Haghpanah, J. Polym. Sci., Part A: Polym. Chem., 2016, 54, 3000-3011.

117 M. Khoshsefat, S. Ahmadjo, S. M. M. Mortazavi, G. H. Zohuri and J. B. P. Soares, New J. Chem., 2018, 42, 8334-8337.

118 L. Zhu, Z. S. Fu, H. J. Pan, W. Feng, C. Chen and Z. Q. Fan, Dalton Trans., 2014, 43, 2900-2906.

119 Q. Xing, K. Song, T. Liang, Q. Liu, W. H. Sun and C. Redshaw, Dalton Trans., 2014, 43, 7830-7837.

120 R. K. Wang, X. L. Sui, W. Pang and C. L. Chen, ChemCatChem, 2016, 8, 434-440.

121 Y. Na, X. Wang, K. Lian, Y. Zhu, W. Li, Y. Luo and C. L. Chen, ChemCatChem, 2017, 9, 1062-1066.

122 S. Takano, D. Takeuchi, K. Osakada, N. Akamatsu and A. Shishido, Angew. Chem., Int. Ed., 2014, 53, 92469250.

123 S. Takano, D. Takeuchi and K. Osakada, Chem. - Eur. J., 2015, 21, 16209-16218.

124 D. Takeuchi, T. Iwasawa and K. Osakada, Macromolecules, 2018, 51, 5048-5054.

125 L. Ding, H. Cheng, Y. Li, R. Tanaka, T. Shiono and Z. Cai, Polym. Chem., 2018, 9, 5476-5482.

126 X. Fu, L. Zhang, R. Tanaka, T. Shiono and Z. Cai, Macromolecules, 2017, 50, 9216-9221.

127 D. B. Culver, H. Tafazolian and M. P. Conley, Organometallics, 2018, 37, 1001-1006.

128 F. Liu, H. Gao, Z. Hu, H. Hu, F. Zhu and Q. Wu, J. Polym. Sci., Part A: Polym. Chem., 2012, 50, 3859-3866.

129 A. Keyes, H. E. Basbug Alhan, U. Ha, Y. S. Liu, S. K. Smith, T. S. Teets, D. B. Beezer and E. Harth, Macromolecules, 2018, 51, 7224-7232.

130 H. Gao, X. Liu, Y. Tang, J. Pan and Q. Wu, Polym. Chem., 2011, 2, 1398-1403.

131 H. Gao, J. Pan, L. Guo, D. Xiao and Q. Wu, Polymer, 2011, 52, 130-137.

132 T. Okada, D. Takeuchi, A. Shishido, T. Ikeda and K. Osakada, J. Am. Chem. Soc., 2009, 131, 10852-10853.

133 D. Takeuchi, J. Am. Chem. Soc., 2011, 133, 11106-11109.

134 J. Gao, Z. H. Ying, L. Zhong, H. Liao, H. Y. Gao and Q. Wu, Polym. Chem., 2018, 9, 1109-1115.

135 J. Gao, L. Zhang, L. Zhong, C. Du, H. Liao, H. Gao and Q. Wu, Polymer, 2019, 164, 26-32.

136 D. Takeuchi and K. Osakada, Polymer, 2016, 82, 392-405.
137 D. Takeuchi, T. Iwasawa and K. Osakada, Macromolecules, 2018, 51, 5048-5054.

138 T. Okada, S. Park, D. Takeuchi and K. Osakada, Angew. Chem., Int. Ed., 2007, 46, 6141-6143.

139 K. Motokuni, D. Takeuchi and K. Osakada, Macromolecules, 2014, 47, 6522-6526.

140 K. Motokuni, D. Takeuchi and K. Osakada, Polym. Chem., 2015, 6, 1248-1254.

141 A. E. Cherian, E. B. Lobkovsky and G. W. Coates, Chem. Commun., 2003, 20, 2566-2567.

142 F. Z. Wang, R. Tanaka, Z. G. Cai, Y. Nakayama and T. Shiono, Polymer, 2017, 127, 88-100.

143 F. Z. Wang, R. Tanaka, Z. G. Cai, Y. Nakayama and T. Shiono, Macromol. Rapid Commun., 2016, 37, 13751381.

144 F. Z. Wang, R. Tanaka, Q. S. Li, Y. Nakayama and T. Shiono, Organometallics, 2018, 37, 1358-1367.

145 C. L. Chen, S. J. Luo and R. F. Jordan, J. Am. Chem. Soc., 2008, 130, 12892-12893.

146 C. Chen and R. F. Jordan, J. Am. Chem. Soc., 2010, 132, 10254-10255.

147 C. Chen, S. J. Luo and R. F. Jordan, J. Am. Chem. Soc., 2010, 132, 5273-5284.

148 M. Kang, A. Sen, L. Zakharov and A. L. Rheingold, J. Am. Chem. Soc., 2002, 124, 12080-12081.

149 S. R. Foley Jr., R. A. Stockland, H. Shen and R. F. Jordan, J. Am. Chem. Soc., 2003, 125, 4350-4361.

150 S. Li and Z. Ye, Macromol. Chem. Phys., 2010, 211, 19171924.

151 L. K. Johnson, L. Wang, S. McLain, A. Bennett, K. Dobbs, E. Hauptman, A. Ionkin, S. D. Ittel, K. Kutnisky, W. Marshall, E. McCord, C. Radzewich, A. Rinehart, K. J. Sweetman, Y. Wang, Z. Yin and M. Brookhart, ACS Symp. Ser., 2003, 857, 131-142.

152 M. Li, X. Wang, Y. Luo and C. L. Chen, Angew. Chem., Int. Ed., 2017, 56, 11604-11609.

153 F. Zhai, J. B. Solomon and R. F. Jordan, Organometallics, 2017, 36, 1873-1879.

154 J. Kiesewetter and W. Kaminsky, Chem. - Eur. J., 2003, 9, 1750-1758.

155 P. Xiang and Z. Ye, J. Polym. Sci., Part A: Polym. Chem., 2013, 51, 672-686.

156 Y. N. Na, D. Zhang and C. L. Chen, Polym. Chem., 2017, 8, 2405-2409.

157 T. Runzi, D. Frohlich and S. Mecking, J. Am. Chem. Soc., 2010, 132, 17690-17691.

158 J. C. Daigle, L. Piche and J. P. Claverie, Macromolecules, 2011, 44, 1760-1762.

159 D. Zhang and C. L. Chen, Angew. Chem., Int. Ed., 2017, 56, 14672-14676.

160 L. H. Guo, C. Zou, S. Y. Dai and C. L. Chen, Polymers, 2017, 9, 122.

161 Z. Chen, W. J. Liu, O. Daugulis and M. Brookhart, J. Am. Chem. Soc., 2016, 138, 16120-16129.

162 Z. Chen, M. D. Leatherman, O. Daugulis and M. Brookhart, J. Am. Chem. Soc., 2017, 139, 16013-16022. 
163 S. X. Zhou and C. L. Chen, Sci. Bull., 2018, 63, 441445.

164 C. C. H. Atienza, T. Diao, K. J. Weller, S. A. Nye, K. M. Lewis, J. G. P. Delis, J. L. Boyer, A. K. Roy and P. J. Chirik, J. Am. Chem. Soc., 2014, 136, 1210812118.

165 G. H. Michael and D. Guironnet, ACS Catal., 2017, 7, 5717-5720.
166 B. K. Long, J. M. Eagan, M. Mulzer and G. W. Coates, Angew. Chem., Int. Ed., 2016, 55, 7222-7226.

167 L. Zhong, G. L. Li, G. D. Liang, H. Y. Gao and Q. Wu, Macromolecules, 2017, 50, 2675-2682.

168 H. Tafazolian, D. B. Culver and M. P. Conley, Organometallics, 2017, 36, 2385-2388.

169 Y. Kanai, S. Foro and H. Plenio, Organometallics, 2019, 38, 544-551. 